\title{
Steroid hormones and neurosteroids in normal and pathological aging of the nervous system
}

\author{
M. Schumacher ${ }^{\mathrm{a}, *}$, S. Weill-Engerer ${ }^{\mathrm{a}}$, P. Liere $^{\mathrm{a}}$, F. Robert ${ }^{\mathrm{a}}$, R.J.M. Franklin ${ }^{\mathrm{b}}$, \\ L.M. Garcia-Segura ${ }^{\text {c}}$, J.J. Lambert ${ }^{\mathrm{d}}$, W. Mayo ${ }^{\mathrm{e}}$, R.C. Melcangi ${ }^{\mathrm{f}}$, \\ A. Parducz ${ }^{\text {g }}$, U. Suter $^{\text {h }}$, C. Carelli ${ }^{\text {a }}$, E.E. Baulieu ${ }^{\text {a }}$, Y. Akwa ${ }^{\text {a }}$ \\ a Inserm U488, 80 rue du Général Leclerc, Kremlin-Bicêtre 94276, France \\ ${ }^{\mathrm{b}}$ Department of Clinical and Veterinary Medicine, University of Cambridge, Madingley Road, Cambridge CB3 OES, UK \\ ${ }^{\mathrm{c}}$ Instituto Cajal, CSIC, 37 Avenida Doctor Arce, Madrid 28002, Spain \\ ${ }^{\mathrm{d}}$ Department of Pharmacology, University of Dundee, Dundee DD1 9SY, UK \\ e Inserm U259, Domaine de Carreire, Bordeaux 33077, France \\ ${ }^{\mathrm{f}}$ Department of Endocrinology, Center of Excellence on Neurodegenerative Diseases, University of Milan, Milan 20133, Italy \\ g Biological Research Center Szeged, Temesvari krt 62, Szeged 6726, Hungary \\ ${ }^{\mathrm{h}}$ Institut of Cell Biology, ETH Hönggerberg, Zürich CH-8093, Switzerland
}

Received 20 June 2003; accepted 11 September 2003

\begin{abstract}
Without medical progress, dementing diseases such as Alzheimer's disease will become one of the main causes of disability. Preventing or delaying them has thus become a real challenge for biomedical research. Steroids offer interesting therapeutical opportunities for promoting successful aging because of their pleiotropic effects in the nervous system: they regulate main neurotransmitter systems, promote the viability of neurons, play an important role in myelination and influence cognitive processes, in particular learning and memory. Preclinical research has provided evidence that the normally aging nervous system maintains some capacity for regeneration and that age-dependent changes in the nervous system and cognitive dysfunctions can be reversed to some extent by the administration of steroids. The aging nervous system also remains sensitive to the neuroprotective effects of steroids. In contrast to the large number of studies documenting beneficial effects of steroids on the nervous system in young and aged animals, the results from hormone replacement studies in the elderly are so far not conclusive. There is also little information concerning changes of steroid levels in the aging human brain. As steroids present in nervous tissues originate from the endocrine glands (steroid hormones) and from local synthesis (neurosteroids), changes in blood levels of steroids with age do not necessarily reflect changes in their brain levels. There is indeed strong evidence that neurosteroids are also synthesized in human brain and peripheral nerves. The development of a very sensitive and precise method for the analysis of steroids by gas chromatography/mass spectrometry (GC/MS) offers new possibilities for the study of neurosteroids. The concentrations of a range of neurosteroids have recently been measured in various brain regions of aged Alzheimer's disease patients and aged non-demented controls by GC/MS, providing reference values. In Alzheimer's patients, there was a general trend toward lower levels of neurosteroids in different brain regions, and neurosteroid levels were negatively correlated with two biochemical markers of Alzheimer's disease, the phosphorylated tau protein and the $\beta$-amyloid peptides. The metabolism of dehydroepiandrosterone has also been analyzed for the first time in the aging brain from Alzheimer patients and non-demented controls. The conversion of dehydroepiandrosterone to $\Delta 5$-androstene- $3 \beta, 17 \beta$-diol and to $7 \alpha-\mathrm{OH}$-dehydroepiandrosterone occurred in frontal cortex, hippocampus, amygdala, cerebellum and striatum of both Alzheimer's patients and controls. The formation of these metabolites within distinct brain regions negatively correlated with the density of $\beta$-amyloid deposits. (C) 2003 Elsevier Ltd. All rights reserved.
\end{abstract}

Abbreviations: AD, Alzheimer's disease; ADIOL, $\Delta 5$-androstene-3 $\beta, 17 \beta$-diol; CNS, central nervous system; DHEA, dehydroepiandrosterone; DHEAS, dehydroepiandrosterone sulfate; $\mathrm{e}^{-}$, electrons; ERT, estrogen replacement therapy; GABA, $\gamma$-aminobutyric acid; GC/MS, gas chromatography/mass spectrometry; HOR, hydroxysteroid oxidoreductase; HPLC, high performance liquid chromatography; HRT, hormone replacement therapy; $3 \beta$-HSD, $3 \beta$-hydroxysteroid dehydrogenase; MBR, mitochondrial benzodiazepine receptor; MCI, mild cognitive impairment; MPA, medroxyprogesterone acetate; NMDA, $N$-methyl-D-aspartate; P0, peripheral myelin protein zero; PMP22, peripheral myelin protein 22; PNS, peripheral nervous system; PR, progesterone receptor; PREG, pregnenolone; PREGS, pregnenolone sulfate; PROG, progesterone; RIA, radioimmunoassay; RT-PCR, reverse transcription-polymerase chain reaction; SERM, selective estrogen receptor modulator; SPRM, selective progesterone receptor modulator; StAR, steroid acute regulatory protein; $3 \alpha, 5 \alpha$-TH PROG, $3 \alpha, 5 \alpha$-tetrahydroprogesterone (allopregnanolone); WHI, Women's Health Initiative

* Corresponding author. Tel.: +33-1-4959-1895; fax: +33-1-4521-1940.

E-mail address: schuma@kb.inserm.fr (M. Schumacher). 


\section{Contents}

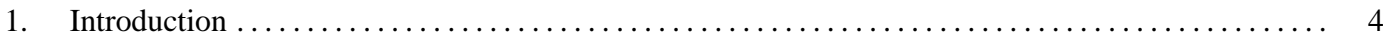

2. Pleiotropic effects of steroids in the nervous system with significance for the aging nervous system 5

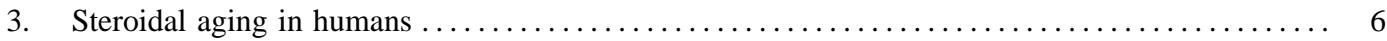

4. Steroids in the aging nervous system: the endocrine glands and local synthesis $\ldots \ldots \ldots \ldots \ldots 7$

5. Levels of steroids in the human nervous system $\ldots \ldots \ldots \ldots \ldots \ldots \ldots \ldots \ldots \ldots \ldots \ldots \ldots . \quad 12$

6. Analysis of steroids by gas chromatography/mass spectrometry $(\mathrm{GC} / \mathrm{MS}) \ldots \ldots \ldots \ldots \ldots \ldots$

7. Analysis of neurosteroids in the brains of aged patients by GC/MS $\ldots \ldots \ldots \ldots \ldots \ldots \ldots \ldots$

8. Age-dependent changes in the nervous system can be reversed by steroids . ............ 15

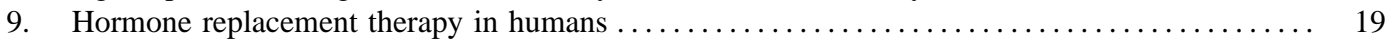

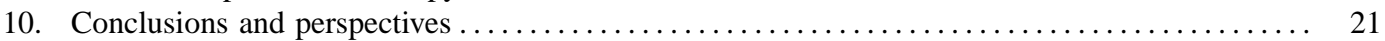

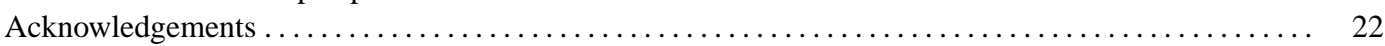

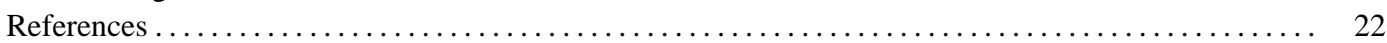

\section{Introduction}

In the developed countries, with the considerable increase in life expectancy, the number of older people will soon surpass that of the younger. This evolution in demography has increased the need for the development of new therapeutical strategies to promote successful aging, defined as low probability of disease, high cognitive and physical capacity and active engagement in life (Rowe and Kahn, 1997; Le Fur et al., 2002). Dementia and in particular Alzheimer's disease (AD), the prevalence of which dramatically increases during aging, will affect a growing number of people and will become one of the main causes of disability among the elderly and a major public health problem (Hebert et al., 2001; Hauw and Duyckaerts, 2002; Sloane et al., 2002). Without progress in preventing or delaying onset of $\mathrm{AD}$, both the number of people with AD disease and the proportion of the total population affected will increase substantially. Epidemiological studies predict that more than 33\% of women and $20 \%$ of men aged 65 years and older will develop dementia, and by the year 2050, cases of dementia will approach the number of cases of cancer (Ott et al., 1998).

Projections indicate that therapies that simply delay the onset of $\mathrm{AD}$ will markedly reduce overall disease prevalence. This is a consequence of the exponential rise in prevalence and incidence of AD with age (Sloane et al., 2002). It has been estimated that delaying the onset of AD by only 5 years would decrease its prevalence by as much as a half (Le Fur et al., 2002). Developing preventive strategies has thus become a main concern. Much effort is actually devoted to the elucidation of the cellular and molecular mechanisms involved in the development of age-dependent dysfunctions and degenerative diseases of the nervous system. It is obvious that multiple factors are involved, involving the genetic background and the environment (Amouyel, 2002). With respect to the prevention of dementia, there is particular interest in the treatment of mild cognitive impairment (MCI), which frequently progresses to dementia (Petersen et al., 2001).
The important question then is whether prevention or treatment of age-dependent nervous dysfunctions and of the resulting cognitive impairments is possible. Recent neuromorphological studies using stereological techniques for counting neuron numbers have provided encouraging news in this respect. They have provided compelling evidence that the loss of neurons during normal aging is much less than previously thought and that cognitive decline observed in aged monkeys and humans is not primarily due to the loss of cortical or hippocampal neurons (Wickelgren, 1996a,b; Peters et al., 1998; Peters, 2002). In the hippocampus and entorhinal cortex, two vulnerable brain regions that are critically involved in memory processes, a massive loss of neurons is only observed in patients with dementia (Gomez-Isla et al., 1996; West et al., 2000). Changes in the aging brain mainly affect cell functions, the size of neurons, the density of neurites and the number of synapses. Alterations of the integrity of myelin sheaths and myelin loss are particularly reliable markers of the aging nervous system and correlate with cognitive decline (Peters, 1996, 2002).

Because changes in the aging nervous system are subtle, it may be possible to reverse them and to improve cognitive performance by pharmacological treatments. The administration of steroids may be particularly promising in this regard: (1) they play an important role in the functioning of the central and peripheral nervous system (CNS and PNS); (2) some steroids have neuroprotective effects; (3) the levels of some neuroactive steroids markedly decrease with age; and (4) unconjugated steroids easily cross the blood-brain barrier and rapidly accumulate throughout the brain. It is indeed now well recognized that the functions of gonadal and adrenal steroid hormones go far beyond reproduction and that they regulate vital neuronal and glial functions by a variety of mechanisms of action (Schumacher and Robert, 2002; Schumacher et al., 2000). In addition, some steroids, named "neurosteroids," can be synthesized within the nervous system by both neurons and glial cells, and the stimulation of their synthesis offers new therapeutical possibilities (Baulieu, 1997; Robel et al., 1999). 
In this review, we shall first describe the multiple effects of steroids in the nervous system, which may be relevant for the aging process. We shall then examine the steroidal aging in humans and present evidence that neurosteroids may also be synthesized within the human nervous system. After a brief survey of recent preclinical evidence that age-dependent dysfunctions of the nervous system can be reversed by the administration of steroids, we shall provide an update of hormone replacement therapy (HRT) in humans. The chapter will conclude with a discussion of possible therapeutical strategies involving steroids.

\section{Pleiotropic effects of steroids in the nervous system with significance for the aging nervous system}

A large number of animal studies support the beneficial effects of estradiol on the functioning and viability of neurons and on learning and memory processes (Garcia-Segura et al., 2001; McEwen, 2001). This steroid, derived from either the circulation or from the local aromatization of androgens, is also thought to play an important role in aging of the brain and of cognitive processes. The potential usefulness of estrogens in preventing or treating age-dependent brain dysfunctions has thus become a major issue.

The neuroprotective effects of estrogens have been documented by many in vivo and in vitro studies. In aged animals and in different lesion paradigms, the treatment with estradiol enhances neuronal survival and recovery (Tanzer and Jones, 1997; Callier et al., 2000; Wise et al., 2000; Garcia-Segura et al., 2001). In culture, estradiol protects neurons against excitatory amino acid and $\beta$-amyloid peptide toxicity, oxidative stress and glucose deprivation (Ferreira and Caceres, 1991; Lorenzo et al., 1992; Behl et al., 1997; Goodman et al., 1996; Green et al., 2000; Zhang et al., 2001). More recently, estradiol has also been shown to promote neurogenesis within the adult hippocampal formation (Gould et al., 2000). An observation that may be particularly relevant for $\mathrm{AD}$ is the decreased generation of $\beta$-amyloid peptides by neuroblastoma cells and by primary cultures of rat, mouse and human embryonic cerebrocortical neurons (Xu et al., 1998). Decreased levels of estrogen in postmenopausal women could thus contribute to the increased risk for the development of neurodegenerative diseases.

Like the estrogens, progestins are also pleiotropic hormones in nervous system and exert neuroprotective effects. In the rat spinal cord, progesterone (PROG) promotes neurological and functional recovery after contusion injury (Thomas et al., 1999) and promotes the survival of ventral motoneurons in the wobbler mouse, a genetic model of spinal cord motor disease (Gonzalez Deniselle et al., 2002). PROG also increases the survival of facial motoneurons after axotomy (Yu, 1989). Particularly remarkable protective effects of PROG have been documented in the rat brain after traumatic injury, which explains why female rats have significantly less edema and show better cognitive recovery than males (Stein, 2001). PROG has also been shown to offer neuroprotection after cerebral ischemia (Jiang et al., 1996).

In addition to its protective effects on nerve cells, PROG is also a signaling molecule involved in the formation of new myelin sheaths, which are necessary for the efficient and rapid conduction of action potentials. This function of PROG is also of significance for the aging brain and peripheral nerves, characterized by the loss of myelin (Peters, 2002). A role of PROG in myelination has first been observed in peripheral nerves, where PROG synthesized by Schwann cells promotes the formation of new myelin sheaths after lesion. Increased myelin formation in response to PROG has also been demonstrated in explant cultures of embryonic rat dorsal root ganglia (DRG), mainly composed of Schwann cells and sensory neurons (Koenig et al., 1995; Schumacher et al., 2001). In this cell culture system, PROG has been shown to accelerate myelin synthesis (Chan et al., 1998).

Progestins regulate myelination in peripheral nerves via two distinct signaling mechanisms, involving either the intracellular PROG receptor (PR) or membrane $\mathrm{GABA}_{\mathrm{A}}$ receptors, which are both expressed by Schwann cells. These two receptor systems are involved in the expression of distinct major peripheral myelin proteins, namely, protein zero (P0) and peripheral myelin protein 22 (PMP22). PROG and $5 \alpha$-dihydroprogesterone, which both bind with high affinity to the intracellular PR, increase expression of P0 expression via this receptor, whereas $3 \alpha, 5 \alpha$-TH PROG increases PMP22 expression by modulating Schwann cell GABA receptors (Melcangi et al., 1999; Magnaghi et al., 2001). Both P0 and PMP22 are encoded by dosage-sensitive genes and are major culprits in motor and sensory neuropathies, which show an increased frequency in the elderly (Suter and Snipes, 1995; Suter and Nave, 1999).

PROG also stimulates myelination by oligodendrocytes in the CNS. This has been shown in organotypic slice cultures of 7-day-old rat and mouse cerebellum. When added to the culture medium, PROG accelerated myelin formation in explant cultures of both males and females. The effect of PROG on myelination involved the intracellular PR: it could be blocked by the PR antagonist mifepristone (RU486), and PROG had no significant effect on myelination in cerebellar slice cultures from PR knockout mice. As in the PNS, $3 \alpha, 5 \alpha$-TH PROG also promoted myelination in a bicuculline-sensitive manner involving $\mathrm{GABA}_{\mathrm{A}}$ receptors. However, as the explant cultures contained many cell types, it is unknown whether $3 \alpha, 5 \alpha-$ TH PROG acted on neuronal or glial $\mathrm{GABA}_{\mathrm{A}}$ receptors (Ghoumari et al., 2003).

The non-reproductive effects of androgens in the nervous system are considerably less well characterized than those of estrogens and progestins. Testosterone influences neuroplastic changes in different nuclei of the limbic system (Johnson et al., 1989; Malsbury and McKay, 1994; De Vries et al., 1994) and also exerts neuroprotective effects, which can be mediated either directly or indirectly via its aromatization to estradiol (Balthazart and Ball, 1998). Work on 
different rodent motoneuron populations, including facial, spinal and pudendal motoneurons, has demonstrated that the administration of testosterone immediately after nerve injury promotes their survival and regeneration through actions mediated by the androgen receptor (Tanzer and Jones, 1997; Jones et al., 2001). Physiological concentrations of testosterone have also been shown to protect primary cultures of human neurons against apoptosis induced by serum deprivation. The effect of testosterone was directly mediated through androgen receptors and did not involve its aromatization to estradiol: (1) it could be mimicked by the non-aromatizable androgen mibolerone; (2) it could be blocked by the antiandrogen flutamide; and (3) it was not prevented by an aromatase inhibitor (Hammond et al., 2001). Testosterone also regulates the production of $\beta$-amyloid peptides by neurons. Treatment of neuroblastoma cells and of rat primary cerebrocortical neurons with testosterone increases the secretion of the non-amyloidogenic $\beta$-amyloid precursor protein (APP) fragment and decreases the secretion of amyloidogenic $\beta$-amyloid peptides (Gouras et al., 2000).

Androgens also play a role in myelination and have been shown to modulate P0 gene expression in the PNS. As Schwann cells do not express the intracellular androgen receptor, different alternative mechanisms by which androgens regulate peripheral myelin gene expression have been proposed: (1) the testosterone metabolite $5 \alpha$-dihydrotestosterone may activate P0 expression by interacting with the PR, which is present in Schwann cells; (2) the testosterone metabolite $3 \alpha, 5 \alpha$-androstane-diol may interact with $\mathrm{GABA}_{\mathrm{A}}$ receptors; and (3) testosterone may influence the myelination process indirectly by acting on the neurons that are myelinated (Magnaghi et al., 1999).

The precursor steroids of estrogens, progestins and androgens, pregnenolone (PREG) and dehydroepiandrosterone (DHEA), also influence neuronal functions and are likely to play a particularly important role in the aging nervous system. Thus, PREG protects mouse hippocampal cells against glutamate and $\beta$-amyloid peptide-induced cell death in a concentration dependent manner. Prevention of glucocorticoid receptor (GR) translocation into the nucleus may be involved in the observed neuroprotective effects of PREG against glutamate neurotoxicity (Gursoy et al., 2001). When administered in vivo, PREG reduced histopathological changes, saved the nervous tissue from secondary lesions and improved the recovery of motor functions after spinal cord injury (Guth et al., 1994). PREG may exert its neuroprotective effects indirectly via its conversion to PROG or by acting directly on spinal cord neurons. Indeed, although PREG is generally considered as a precursor for biologically active steroids, a recent study has shown that PREG itself may influence the dynamics of the neuronal cytoskeleton by binding to the microtubule-associated protein 2 (MAP-2; Murakami et al., 2000).

The sulfated form of PREG (PREGS) is a potent steroidal enhancer of memory processes in rodents (Isaacson et al., 1995; Mayo et al., 1993; Ladurelle et al., 2000). It has been shown to prevent amnesia induced by pharmacological agents (Flood et al., 1992, 1995; Mathis et al., 1994, 1996) and to reverse age-dependent memory deficits (Vallée et al., 1997). The mechanisms underlying the promnesic actions of PREGS involve the modulation of neurotransmitter systems, including the $N$-methyl-D-aspartate (NMDA)-glutamatergic system (Mathis et al., 1994; Maurice et al., 1998; Akwa et al., 2001), $\sigma 1$ receptors (Urani et al., 1998; Reddy and Kulkarni, 1998) and the central cholinergic system (Meziane et al., 1996; Darnaudéry et al., 1998). It has been proposed that PREGS may stimulate cholinergic neurotransmitter pathways that are critically involved in learning and memory by inhibiting the GABAergic innervation of cholinergic forebrain neurons, resulting in enhanced acetylcholine release within the cerebral cortex, amygdala and hippocampus (Darnaudéry et al., 1998; Pallarés et al., 1998; Vallée et al., 2001).

A large number of animal studies have documented beneficial effects of DHEA on obesity, diabetes, cancer, heart disease, immune and nervous functions (Bellino et al., 1995; Kalimi and Regelson, 1990). With respect to the latter, the neurotrophic and neuroprotective effects of DHEA and its sulfate DHEAS have been documented. Nanomolar concentrations of DHEA or DHEAS promote the survival and differentiation of cultured neurons (Bologa et al., 1987). Both steroids also protected hippocampal neurons from the toxic effects of glutamate (Cardounel et al., 1999) and stimulate neurite growth in cultures of cortical neurons isolated from embryonic rat brains by modulating the activity of NMDA receptors (Compagnone and Mellon, 1998). When administered in vivo, DHEAS significantly attenuated learning impairments induced by the administration of the NMDA antagonist dizocilpine and of the muscarinic acetylcholine receptor antagonist scopolamine (Maurice et al., 1997; Urani et al., 1998). Treatment of adult rats with DHEA has also recently been shown to stimulate the proliferation of granule neurons within the hippocampal formation by antagonizing the inhibitory effects of glucocorticosteroids (Karishma and Herbert, 2002).

Particularly relevant to the aging process and AD may be the observations that DHEA or DHEAS improve memory performance in aging mice (Flood and Roberts, 1988), and that PREG, DHEA and their sulfate esters protect against $\beta$-amyloid peptide-induced neurotoxicity and amnesia (Cardounel et al., 1999; Maurice et al., 1998).

\section{Steroidal aging in humans}

The blood levels of specific gonadal and adrenal steroids continuously decrease with age. In women, the abrupt decrease in ovarian estradiol and PROG at the time of the menopause leads to a series of physical and emotional symptoms and increased risk of cardiovascular diseases, osteoporosis and dementia, in particular of AD (Khaw, 1992; Sowers and La Pietra, 1995; Wise et al., 1999; Burger et al., 
2002). Measures of estrogen levels in women with $A D$ have provided conflicting results. Some studies have not shown significant differences between healthy women and women with AD (Cunningham et al., 2001). On the contrary, other studies have found decreased levels of estradiol in AD patients (Manly et al., 2000). One study has reported decreased estradiol levels in the cerebrospinal fluid of $\mathrm{AD}$ patients and a negative correlation with $\beta$-amyloid levels (Schonknecht et al., 2001).

Circulating levels of PROG do not significantly change with age in men (Vermeulen and Verdonck, 1976; Belanger et al., 1994). That is, circulating PROG is exclusively of adrenal origin in men and its production can be stimulated by the administration of ACTH and inhibited by dexamethasone, a synthetic glucocorticoid that exerts suppressive effects on pituitary and adrenal activity (Gutai et al., 1977). However, plasma levels of the $\mathrm{GABA}_{\mathrm{A}}$ receptor-active PROG metabolite $3 \alpha, 5 \alpha-$ TH PROG significantly decease after the age of 40 years in men, whereas they remain almost constant in women between the age of 20 and 70 years (Genazzani et al., 2002).

The decrease in testosterone production by the testes is progressive, and in men, there is no state analogous to the menopause. Total serum testosterone decreases by about $30 \%$ and free testosterone by as much as $50 \%$ between age 25 and 75 years (Vermeulen, 1991; Morley et al., 1997b). As testosterone is an anabolic steroid, reduced androgen levels with age lead to decreased muscle strength and bone mass (van den Beld and Lamberts, 2002). In a cross-sectional survey of healthy males, bioavailable testosterone correlated negatively with age and in comparison with other steroids correlated best with cognitive and physical measures (Morley et al., 1997a).

Circulating testosterone not only decreases in men with progressing age, but also in women, as a consequence of the age-dependent decline in ovarian and adrenal androgen production. The mid-cycle rise in free testosterone and androstenedione seen in younger women (19-37 years old) is consistently absent in older women (43-47 years old; Mushayandebvu et al., 1996). The $24 \mathrm{~h}$ mean plasma concentrations of total and of free testosterone also show a steep diminution with age in healthy women between 21 and 51 years of age (Zumoff et al., 1995). The decrease in free testosterone observed in older women can be further amplified by estrogen replacement therapy (ERT) because of the suppression of the pituitary-gonadal axis (Mathur et al., 1985).

The levels of two very abundant adrenal steroids, DHEA and DHEAS, show a marked gradual reduction with progressing age in both men and women (Orentreich et al., 1984; Ravaglia et al., 1996; Labrie et al., 1997b; Nafziger et al., 1998; Laughlin and Barrett-Connor, 2000; Mazat et al., 2001). Whether there is a link between reduced levels of DHEA or DHEAS and AD is still a controversial issue. Most studies have not found differences in DHEAS levels between $\mathrm{AD}$ patients and non-demented patients (Legrain et al., 1995; Yanase et al., 1996; Carlson et al., 1999; Ferrario et al., 1999), whereas two studies have reported decreased levels of DHEAS in AD patients (Leblhuber et al., 1993; Murialdo et al., 2000). No apparent relationship between circulating levels of DHEAS and cognitive performance in the elderly has been found (Barrett-Connor and Edelstein, 1994; Carlson and Sherwin, 1999; Kalmijn et al., 1998; Mazat et al., 2001; Yaffe et al., 1998a). A significant decrease in plasma PREG and PREGS also occurs in men and women. This was shown in 56 healthy males, ranging in age from 20 to 84 years (Morley et al., 1997a).

In contrast to most steroids, the adrenal production of glucocorticoids is maintained throughout life (Herbert, 1995). However, the brain may become more sensitive to circulating cortisol with progressing age because of the marked decrease in DHEA, which acts as an antiglucocorticoid (Kimonides et al., 1999; McIntosh et al., 1993). Increased levels of cortisol may represent a risk factor for the development of neurodegenerative diseases (McEwen et al., 1999; Nichols et al., 2001). Brain imaging techniques have allowed to show that aging subjects with increased cortisol levels show a reduction in hippocampal volume and decreased attention and memory performance. Whether these changes predict the development of dementia or whether they are reversible is unknown (Lupien et al., 1998, 1999).

\section{Steroids in the aging nervous system: the endocrine glands and local synthesis}

Steroid hormones synthesized by the gonads and adrenal glands easily cross the blood-brain and the blood-nerve barriers and rapidly accumulate within the nervous tissues, except for their conjugated forms such as the steroid sulfates, which not easily enter the brain (see Wang et al., 1997). In addition, as already mentioned above, neurosteroids can be synthesized within the CNS and PNS by neurons and glial cells (Robel et al., 1999; Baulieu et al., 2001). To qualify as a neurosteroid, there are two requirements: (1) persistence of the steroid in the nervous system in the absence of the steroidogenic endocrine glands (gonads and adrenal glands); and (2) expression and activity of the enzymes involved in their synthesis. The work that has established the biosynthetic pathways of neurosteroids in the nervous system of experimental animals has already been extensively reviewed (Robel et al., 1999; Mensah-Nyagan et al., 1999; Tsutsui et al., 2000; Mellon et al., 2001; Mellon and Vaudry, 2001), and this review will focus on neurosteroid biosynthesis and metabolism in the human nervous system.

As both the endocrine glands and the local production contribute to the pool of steroids present in the nervous tissues, the age-dependent changes in circulating levels of steroid hormones, which have been described in Section 3 on steroidal aging, not necessarily reflect changes in brain levels. Whether the synthesis of neurosteroids changes with age and plays a role in the aging process, eventually by 
compensating for the age-dependent decrease in circulating hormones, needs to be explored. That is, the question of the biological significance of neurosteroid synthesis in the brain and in peripheral nerves has so far been directly addressed only by a few studies. Thus, there is evidence that the local synthesis of PROG in peripheral nerves may play a role in myelination: (1) Schwann cells convert PREG to PROG and express the $3 \beta$-hydroxysteroid dehydrogenase (3ß-HSD), the enzyme involved in this reaction, in response to a neuronal signal (Robert et al., 2001); (2) after cryolesion of the mouse sciatic nerve, blocking either the local synthesis or the local activity of PROG during the process of regeneration strongly inhibits the formation of new myelin sheaths (Koenig et al., 1995); and (3) in DRG explant cultures, mRNA levels of enzymes involved in the de novo synthesis of PROG, namely the cytochrome P450scc (enzyme that converts cholesterol to PREG) and the $3 \beta-H S D$, are markedly increased during the peak of myelin formation (Chan et al., 1998).

Results of another study suggest that the formation of conjugated PREG within the hippocampus, a brain region critically involved in spatial memory, may play an important role in memory processes and in the aging of cognitive performances. Levels of conjugated PREG were found to be selectively reduced in the hippocampus in 2-year-old rats with memory deficits. Most importantly, the memory deficits of cognitively impaired aged rats could be transiently corrected by intrahippocampal injection of PREGS. This study strongly suggests that the local synthesis of neurosteroids within distinct brain regions may be necessary for the maintenance of cognitive functions during aging (Vallée et al., 1997).

The contribution of endogenous neurosteroids to the antiamnesic effects of $\sigma 1$ receptor agonists has been examined in mice deprived of their steroidogenic endocrine glands by castration and adrenalectomy to avoid the confusing effects of circulating steroids. Blocking the local synthesis of PROG in the brain increased (+)- $\left[{ }^{3} \mathrm{H}\right] \mathrm{SKF}-10047$ binding to $\sigma 1$ receptors and facilitated the antiamnesic effects of the $\sigma 1$ receptor agonist PRE-084, whereas increasing the accumulation of locally synthesized PROG decreased $\sigma 1$ receptor binding and prevented the PRE-084 effect (Phan et al., 1999).

Local aromatization of circulating androgens to estradiol in the brain plays an important role during regeneration. It has recently been shown that expression of the aromatase, an enzyme that converts androgens to estrogens, is induced in reactive astrocytes near the lesion site (Garcia-Segura et al., 1999) and that locally formed estradiol promotes the viability of neurons in synergy with the peptide growth factor IGF-1 (Cardona-Gomez et al., 2001). Whether estradiol formed in the brain form circulating testosterone can be considered as a neurosteroid is a question of definition. Initially, the term "neurosteroid" referred to such steroids that either are or can be synthesized de novo from cholesterol within the nervous system (Baulieu, 1991). However, in the literature, the term "neurosteroid" is also frequently applied to steroid metabolites that are formed from circulating hormones within the brain such as estradiol. The problem is that these metabolites, in contrast to de novo synthesized steroids, disappear from the nervous tissues after chirurgical removal of the steroidogenic endocrine glands. That is, persistence in the brain after castration and adrenalectomy was initially proposed as a criterion for the identification of a neurosteroid (Corpéchot et al., 1981; Baulieu, 1991). Another term that is regularly used in a broader sense is the one of "neuroactive steroid". Initially, this term was proposed for all natural or synthetic steroids that can rapidly alter the excitability of neurons by binding to membrane-bound receptors such as those for inhibitory or excitatory neurotransmitters (Paul and Purdy, 1992). However, it is now frequently used to designate steroids with biological activity in the nervous system.

Over the past years, evidence has accumulated that neurosteroids may also be synthesized and metabolized in the human nervous system (the metabolic pathways of steroids are presented in Figs. 1 and 2). The mitochondrial cytochrome P450scc, which catalyzes the conversion of cholesterol to PREG, was first found in the human brain by immunocytochemistry (Le Goascogne et al., 1989). Several studies have described the presence of P450scc mRNA in different regions of the human brain. In the hippocampus of patients with temporal lobe epilepsy, P450scc mRNA has been quantified by competitive RT-PCR. Its levels were about 200 times lower than in the adrenal gland and were higher in the hippocampus of women than of men (Beyenburg et al., 1999; Watzka et al., 1999). In another study, the mRNAs of the P450scc and of the steroid acute regulatory protein (StAR), which plays a critical role in the intramitochondrial transport of cholesterol and steroid synthesis, have been detected by RT-PCR in the cerebral cortex pons, cerebellum and hippocampus of men and women (Inoue et al., 2002). The presence of P450scc mRNA has also been detected by real-time RT-PCR in human amygdala, caudate nucleus, cerebellum, corpus callosum, hippocampus, spinal cord and thalamus (Yu et al., 2002).

Activity of the P450scc has so far not been reported for human brain tissue, but has recently been examined in human brain cell lines with characteristics of either oligodendrocytes (myelin basic protein expression), astrocytes (glial fibrillary acidic protein expression) or neurons (neurofilament expression). Oligodendrocytes, but not astrocytes and neurons, converted tritiated precursors to PREG. The cells also expressed P450scc and mitochondrial benzodiazepine receptor (MBR, also called peripheral benzodiazepine receptor) mRNA and protein (Brown et al., 2000). Like the StAR protein, the MBR is involved in the transport of cholesterol into the mitochondria and agonists of this receptor have been shown to increase the synthesis of steroids (Culty et al., 1999; Stocco, 2001).

PREG is then converted to PROG by the $3 \beta-H S D$. This enzyme can use many $3 \beta$-hydroxysteroids as substrates and 
<smiles>CC(C)CCCC(C)C1CCC2C3CC=C4CC(O)CCC4(C)C3CCC12C</smiles>

Cholesterol<smiles>CC(=O)C1CCC2C3CC=C4CC(O)CCC4(C)C3CCC12Cc1ccccc1</smiles>

Pregnenolone<smiles>CC(=O)C1(O)CCC2C3CC=C4CC(O)CCC4(C)C3CCC21C</smiles>

$17 \alpha-H y d r o x y p r e g n e n o l o n e$
(6)<smiles>CC12CCC3C(CC=C4CC(O)CCC43C)C1CCC2=O</smiles>

Dehydroepiandrosterone<smiles>CC(O)C1CCC2C3CCC4=CC(=O)CCC4(C)C3CCC12C</smiles>

$20 \alpha$-Dihydroprogesterone

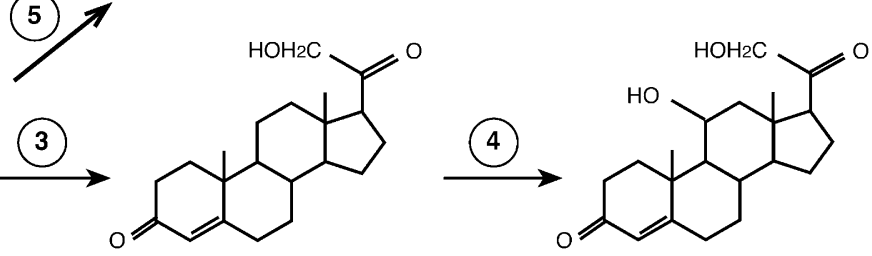

Progesterone

Deoxycorticosterone

Corticosterone

(6)<smiles>CC(=O)C1(O)CCC2C3CCC4=CC(=O)CCC4(C)C3CCC21C</smiles><smiles>CC(=O)C1(O)CCC2C3CCC4=CC(=O)CCC4(C)C3CCC21C</smiles>

Deoxycortisol<smiles>CC(=O)C1(O)CCC2CC3(C1)C1C(O)CCC34CCC(=O)C=C4CCC21</smiles>

Cortisol<smiles>c1ccccc1</smiles><smiles>Cc1ccccc1CS(=O)C1CCC2C3CCC4=CC(=O)CCC4(C)C3CCC21C</smiles>

Androstenedione

Estrone

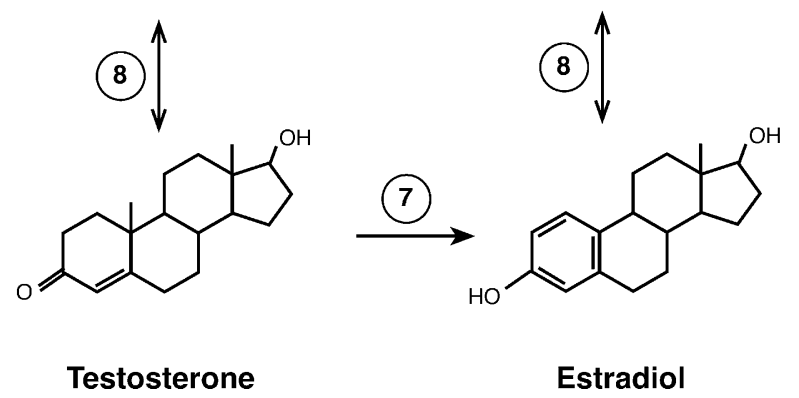

Fig. 1. Biosynthetic pathways of steroids. Conversion of cholesterol to pregnenolone is catalyzed by the cytochrome P450scc (1) (scc: side chain cleav-

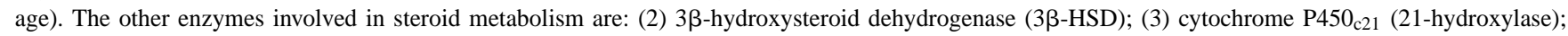

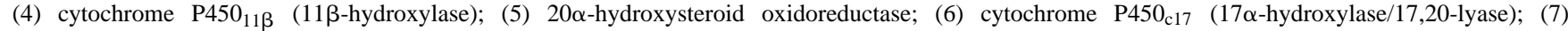
17 $\beta$-hydroxysteroid oxidoreductases (17 $\beta$-HOR); (8) aromatase. 
(a)<smiles>CC(=O)C1CCC2C1CCC1C2CCC2=CC(=O)CCC21C</smiles>

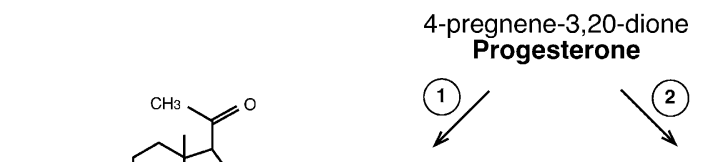<smiles>CC1CCCC1C1CCC2CC(=O)CCC21C</smiles>

$5 \alpha$-pregnane-3,20-dione $5 \alpha$-Dihydroprogesterone<smiles></smiles>

$5 \alpha$-pregnane- $3 \alpha$-ol-20-one $3 \alpha, 5 \alpha$-Tetrahydroprogesteron (Allopregnanolone)
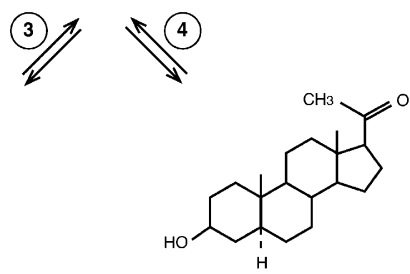

$5 \alpha$-pregnane-3 $\beta$-ol-20-one $3 \beta, 5 \alpha-$ Tetrahydroprogesterone (Iso-allopregnanolone)

(b)

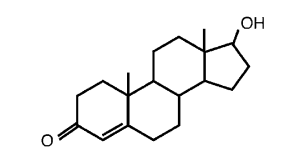

4-androstene -17 $\beta$-ol-3-one

Testosterone<smiles>O=C1CCC2(CC1)C(O)CCC1C3CCC(O)C3CCC12</smiles>

$5 \alpha$-androstane-17 $\beta$-ol-3-one

$5 \alpha$-Dihydrotestosterone

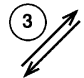<smiles>OC1CCC2C(CCC3C(O)CCC32)C1</smiles>

$3 \alpha, 5 \alpha$-androstane-3.17-diol $3 \alpha, 5 \alpha-$-Tetrahydrotestosterone<smiles>C1=C[CH-]1</smiles>

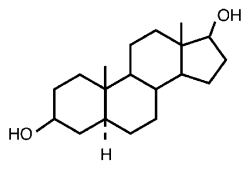

$3 \beta, 5 \alpha$-androstane-3.17-diol $3 \beta, 5 \alpha-$-Tetrahydrotestosterone<smiles>CC(=O)C1CCC2C1CCC1C3CCC(=O)CC3CCC12</smiles>

$5 \beta$-pregnane-3,20-dione $5 \beta$-Dihydroprogesterone

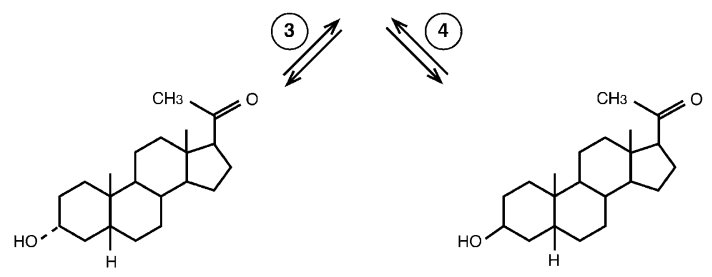

$5 \beta$-pregnane-3 $\alpha$-ol-20-one $3 \alpha, 5 \beta$-Tetrahydroprogesterone (Pregnanolone)
$5 \beta$-pregnane-3 $\beta$-ol-20-one 3 $\beta, 5 \beta$-Tetrahydroprogesterone (Iso-pregnanolone)

Fig. 2. Reductive metabolic pathways of progesterone (a) and testosterone (b). Enzymes involved: (1) $5 \alpha$-reductase; (2) $5 \beta$-reductase; (3) $3 \alpha$-hydroxysteroid oxidoreductase ( $3 \alpha-\mathrm{HOR})$; (4) $3 \beta$-hydroxysteroid oxidoreductase ( $3 \beta$-HOR).

also converts DHEA to androstenedione. The full name of the enzyme is $3 \beta$-hydroxysteroid dehydrogenase $/ \Delta_{5}-\Delta_{4}$ isomerase, because it catalyzes two reactions on separate active sites, located on a single protein: the dehydrogenation of $3 \beta$-hydroxysteroids ( $3 \beta$-HSD activity) and the subsequent isomerization of $\Delta_{5}$-3-ketosteroids (double bond between $\mathrm{C} 5$ and C6) to $\Delta_{4}-3$-ketosteroids (double bond between $\mathrm{C} 4$ and C5; ketosteroid isomerase (KSI) activity). The cDNAs of two human isoforms (types I and II) have been isolated, respectively, from placenta and adrenal glands and the corresponding genes, located on chromosome 1 , have been cloned (Lachance et al., 1990, 1991). Mutations in the type II gene, which is predominantly expressed in the adrenal glands and gonads, have been related to different forms 
of congenital adrenal hyperplasia associated with pseudohermaphroditism (Simard et al., 1995). Yu et al. (2002) have quantified $3 \beta-H S D$ mRNA by real-time RT-PCR in the human amygdala, caudate nucleus, cerebellum, corpus callosum, hippocampus, spinal cord and thalamus. The primers used in their study did not allow to distinguish between the type I and II isoforms. The $3 \beta$-HSD mRNA was present in all brain regions examined and highest levels were found in the myelin-rich corpus callosum and in the spinal cord ( $\mathrm{Yu}$ et al., 2002). Both 3 $\beta$-HSD and PR mRNA were found to be present within distinct regions, suggesting local synthesis and autocrine/paracrine actions of PROG in the human brain (Inoue et al., 2002). Cultured human oligodendroglial, astroglial and neuronal cell lines all expressed the 3 $\beta$-HSD (Brown et al., 2000). The observation that human glioma cells with an oligodendroglial phenotype (expressing the myelin basic protein) express both P450scc and 3 $\beta$-HSD suggests that human oligodendrocytes may have the capacity to synthesize PROG de novo from cholesterol (Brown et al., 2000).

PREG can also be converted to DHEA and PROG to androstenedione by the cytochrome $\mathrm{P} 450_{\mathrm{c} 17}(17 \alpha$-hydroxylase/ 17,20-lyase). $\mathrm{P} 450_{\mathrm{c} 17} \mathrm{mRNA}$ has been detected by real-time PCR in different regions of the human brain (Yu et al., 2002). Although one study has failed to demonstrate $\mathrm{P} 450_{\mathrm{c} 17}$ activity in human brain cell lines (Brown et al., 2000), it is very likely that the enzyme expressed in human brain is functional. In fact, brain $\mathrm{P} 450_{\mathrm{c} 17}$ activity appears to be conserved through the vertebrate phylum and has been demonstrated in amphibians (Mensah-Nyagan et al., 1999), birds (Matsunaga et al., 2001) and rodents (Zwain and Yen, 1999a,b). An alternative mechanism of DHEA formation has been observed in human glial cells. In these cells, DHEA may be synthesized through a cytochrome $\mathrm{P}_{450} \mathrm{c}_{\mathrm{c} 7}$-independent and $\mathrm{Fe}^{2+}$-dependent pathway as has been previously described for cultured rat oligodendrocytes and astrocytes (Cascio et al., 2000). Thus, the treatment of human oligodendrocytes and astrocytes, but not neurons, with $\mathrm{FeSO}_{4}$, induced the formation of DHEA. The synthesis of DHEA could not be blocked by the $\mathrm{P}^{4} 50_{\mathrm{c} 17}$ inhibitor SU 10603, indicating that the enzyme was not involved. Interestingly, the treatment of human oligodendrocytes with $\beta$-amyloid peptides, which increased the formation of reactive oxygen species (ROS), also increased DHEA formation (Brown et al., 2000). This observation suggests that the local synthesis of DHEA by glial cells in response to ROS and $\beta$-amyloid peptides may play an important role in neuronal survival.

DHEA is further converted to a series of metabolites and these metabolic pathways are likely to regulate its levels and activity in the brain. As already mentioned, the $3 \beta-H S D$ converts DHEA to the androgen androstenedione. The $17 \beta$-hydroxysteroid oxidoreductases (17 $\beta$-HORs, also called $17 \beta$-hydroxysteroid dehydrogenase), which catalyze the final steps of androgen and estrogen biosynthesis (androstenedione $\leftrightarrow$

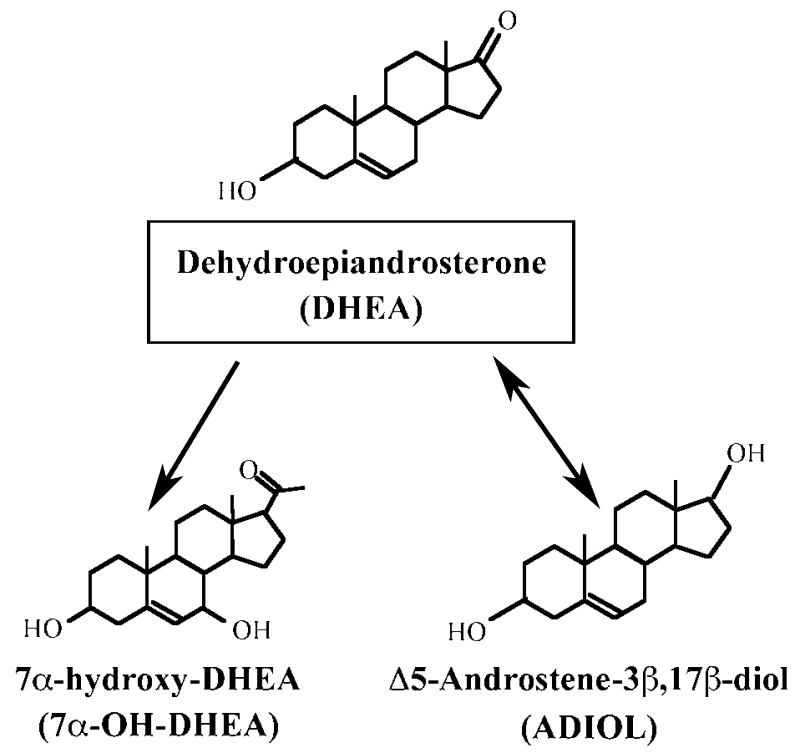

Fig. 3. Metabolism of dehydroepiandrosterone to $\Delta 5$-androstene$3 \beta, 17 \beta$-diol by the $17 \beta$-hydroxysteroid oxidoreductases and to $7 \alpha-\mathrm{OH}$ dehydroepiandrosterone by the $7 \alpha$-hydroxylase $\left(\mathrm{P}_{450} \mathrm{c} 7\right)$, as it occurs in the aging brain from Alzheimer's patients and non-demented controls (modified from Weill-Engerer et al., 2003).

testosterone and estrone $\leftrightarrow$ estradiol), also convert DHEA to $\Delta 5$-androstene-3 $\beta, 17 \beta$-diol (ADIOL). The mRNAs encoding the $17 \beta$-HORs isozymes $1,3,4$ and 5 have also been detected and quantified in human brain and their respective levels showed no significant differences between men and women (Steckelbroeck et al., 2001b; Beyenburg et al., 2000). 17ß-HOR activity has been demonstrated in human fetal brain, in meningiomas (Knapstein et al., 1968; Jenkins and Hall, 1977; Carlson et al., 1994) and in temporal lobe biopsies from men and women suffering from epilepsy, and again, no sex differences were observed (Steckelbroeck et al., 1999b). When human SH-SY5Y neuroblastoma cells are incubated with testosterone, they form large amounts of androstenedione, indicative of catalysis by highly active 17ß-HOR (Wozniak et al., 1998).

In addition to its conversion to ADIOL by the $17 \beta-$ HORs, DHEA is also converted by a $7 \alpha$-hydroxylase $\left(\mathrm{P} 450_{\mathrm{c}}\right)$ to $7 \alpha-\mathrm{OH}-\mathrm{DHEA}$. The activity of this enzyme has recently been demonstrated in the human brain of both sexes. It is significantly higher in the cerebral cortex than in the subcortical white matter from biopsies (Steckelbroeck et al., 2002). The biological significance of $7 \alpha-\mathrm{OH}-\mathrm{DHEA}$ and ADIOL in the brain still needs to be elucidated. In peripheral tissues, both metabolites have been found to up-regulate immunity and to counteract immunosuppression (Padgett and Loria, 1994; Hampl et al., 1997; Morfin et al., 2000; Lathe, 2002; Loria, 2002).

The metabolism of DHEA to ADIOL and to $7 \alpha-\mathrm{OH}-$ DHEA has recently been studied for the first time in the aging brain from $\mathrm{AD}$ patients and non-demented controls (age: 75-91 years; Weill-Engerer et al., 2003) (Fig. 3). The 
formation of these metabolites occurred in frontal cortex, hippocampus, amygdala, cerebellum and striatum of both $\mathrm{AD}$ patients and controls. Regional differences were observed in the two groups, with significantly higher formation of $7 \alpha$-OH-DHEA in the frontal cortex compared to other brain regions, and of ADIOL in cerebellum and striatum compared to frontal cortex. Interestingly, a trend toward a negative correlation was found between the density of cortical $\beta$-amyloid deposits and the amount of $7 \alpha-\mathrm{OH}-\mathrm{DHEA}$ formed in the frontal cortex and that of ADIOL formed in the hippocampus (Weill-Engerer et al., 2003).

The enzymes involved in the metabolism of PROG and of testosterone were found to be expressed in the human brain. Levels of different mRNAs encoding the $5 \alpha$-reductase 1 , the $3 \alpha$-hydroxysteroid oxidoreductases ( $3 \alpha$-HORs) 2 and 3 and the $20 \alpha$-hydroxysteroid dehydrogenase have been quantified by real-time RT-PCR in the hippocampus and temporal lobe cortex from patients with pharmacoresistant temporal lobe epilepsy. Interestingly, plasma levels of $3 \alpha, 5 \alpha-\mathrm{TH}$ PROG did not correlate with mRNA expression levels of the enzymes involved in its synthesis (Stoffel-Wagner et al., 2003). In this study, the $3 \alpha-\mathrm{HOR}$ was referred to as $3 \alpha$-hydroxysteroid dehydrogenase ( $3 \alpha-\mathrm{HSD})$. In this review, we use the term $3 \alpha-\mathrm{HOR}$ according to the recently suggested nomenclature of enzymes involved in steroid metabolism (Baulieu et al., 1999), because the reaction catalyzed by the enzyme is reversible.

The enzymatic activity of the $5 \alpha$-reductase has first been demonstrated in human brain tissues by using either PROG or testosterone as substrates (Jenkins and Hall, 1977; Saitoh et al., 1982). The enzymatic activities of the $5 \alpha$-reductase and the $3 \alpha-\mathrm{HOR}$ were found to colocalize at all life stages in the cerebral cortex and subcortical white matter of both men and women, but no sex-specific differences in enzyme activities were observed (Steckelbroeck et al., 2001a). The human neuroblastoma cells SH-SY5Y actively metabolize PROG and testosterone to their respective $5 \alpha$-reduced metabolites. Differentiation of the neuroblastoma cells is paralleled by a significant increase in the expression of the $5 \alpha$-reductase 1 and of the formation of $5 \alpha$-reduced steroid metabolites (Maggi et al., 1998). When homogenates from human male and female frontal cortex were incubated with testosterone, not only $5 \alpha$-dihydrotestosterone but also $5 \beta$-dihydrotestosterone was formed in significant amounts (Wozniak et al., 1998). It has been proposed that $5 \beta$-reduction of steroids may correspond to an inactivation pathway, thus regulating the amount of substrate available for the formation of biologically active metabolites (Hutchison and Steimer, 1981; Steimer and Hutchison, 1981). In addition, $5 \beta$-reduced metabolites of testosterone may directly inhibit the activity of enzymes, such as the aromatase, involved in the formation of neuroactive steroids (Schumacher et al., 1991).

An interesting question is whether the human brain has the potential for glucocorticoid synthesis, because the mRNAs for all the enzymes required for the synthe- sis of cortisol from cholesterol have been detected. The cytochrome $\mathrm{P}^{2} 50_{21}$ converts PROG and $17 \alpha-\mathrm{OH}-\mathrm{PROG}$ to 11-deoxycorticosterone and 11-deoxycortisol. Humans have two $\mathrm{P}^{4} 0_{21}$ genes, one of which is an inactive pseudogene (White et al., 1985). In an early study, the activity of the enzyme was demonstrated in human fetal brain, but its mRNA was not detected by solution hybridization (Mellon and Miller, 1989). More recently, very low levels of cytochrome $\mathrm{P}^{4} \mathrm{O}_{21}$ mRNA have been detected in the human hippocampus, at levels about 10,000 times lower than those measured in adrenal gland tissue (Beyenburg et al., 2001). Transcripts of the cytochromes $P 450_{21}$ and $P 450_{11 \beta}$, which catalyze the final steps in the synthesis of glucocorticoids (11-deoxycorticosterone $\rightarrow$ corticosterone and 11-deoxycortisol $\rightarrow$ cortisol), have also been measured in different regions of the human brain by real-time RT-PCR. Cytochrome $\mathrm{P}_{450_{21}}$ was expressed in the amygdala, caudate nucleus, cerebellum, corpus callosum, hippocampus, thalamus and spinal cord and cytochrome $\mathrm{P} 450_{11 \beta}$ in all these regions, except in the cerebellum and hippocampus. Depending on the brain region, mRNA levels were 100-10,000 times less than in the adrenal gland (Yu et al., 2002).

The activity of the aromatase, the enzyme that converts androgens to estrogens, has been characterized in microsomal preparations of temporal lobe biopsies as well as in cerebral cortex and subcortical white matter samples of adults and children with epilepsy. Aromatase activity was found to be higher in cerebral cortex than in white matter, but no differences were observed between sexes or ages (Steckelbroeck et al., 1999a). Another study has examined aromatase activity in the human neuroblastoma cell line SH-SY5Y and in human postmortem brain samples of AD and control patients. The aromatase activity in differentiated neuroblastoma cells was lower than in undifferentiated cells. Homogenates of adult human male and female cortex and frontal and temporal areas of both $\mathrm{AD}$ and control patients all showed considerably lower enzyme activity than the neuroblastoma cells. The temporal cortical area had significantly higher aromatase activity than the frontal one. No significant difference in aromatase activity was observed between control and AD brains (Wozniak et al., 1998).

\section{Levels of steroids in the human nervous system}

Because steroids can be synthesized within the nervous system and because they may differently accumulate within distinct compartments of the nervous system, their blood levels do not necessarily reflect their concentrations and bioavailability in the brain and in peripheral nerves. Only a few studies have investigated the distribution of neurosteroid concentrations in human brain by radioimmunoassay (RIA; Lanthier and Patwardhan, 1986; Lacroix et al., 1987; Hammond et al., 1983; Bixo et al., 1997). Measurements of neurosteroids in postmortem human brains are associated with great difficulties, and they need to be cautiously 
interpreted because material is obtained by autopsy, and the conditions of death, tissue sampling and storage cannot be subject to the same degree of control as in animal experiments. The delay from death to storage is generally as long as $24-48 \mathrm{~h}$, which may significantly affect the brain content of steroids and of their metabolites. Recently, it has been reported that cells in slices from adult human postmortem brain can survive for extensive periods (Verwer et al., 2000). The endocrinological and neurological status of the patients need to be taken into account.

The data of two studies indicate that PREG and DHEA are the most abundant steroids in the human brain, values for PREG being greater than those for DHEA (Lanthier and Patwardhan, 1986; Lacroix et al., 1987). They also show that high levels of steroids are still present in the brains of aged patients. In the study of Lanthier and Patwardhan (1986), based on three men and two women (age: 56-75 years), no marked differences in the concentrations of PREG, DHEA, PROG, androstenedione, testosterone, estradiol and estrone were observed between different brain regions, including the hypothalamus, amygdala, hippocampus and different parts of the cerebral cortex. The small number of samples did not indicate sex differences in brain steroid levels, except for somewhat higher DHEA levels in the two women. In the study of Lacroix et al. (1987), based on nine women and one man (age: 76-93 years), levels of PREG, PROG, $17 \alpha-\mathrm{OH}-\mathrm{PROG}$, androstenedione and DHEA varied little among different brain regions, including the cerebral cortex, cerebellum and corpus callosum. The concentrations of these steroids were seven to nine times higher in brain tissue when compared to plasma, suggesting their accumulation or local synthesis in the brain.

In another study, the concentrations of PROG, androstenedione, testosterone, 5 $\alpha$-dihydrotestosterone and androsterone have been measured in different brain regions of four male (age: $2.5-58$ years) and four female (age: 4-82 years) cadavers (Hammond et al., 1983). Because of the limited number of samples and the wide range of ages, it is difficult to draw firm conclusions from this work. In the adult brains, no differences were observed for the concentrations of steroids between different regions (amygdala, hypothalamus, parietal cortex) and between sexes, with the exception of higher testosterone levels in men as compared to women.

In a more recent study, levels of PROG, $5 \alpha$-dihydroprogesterone and $3 \alpha, 5 \alpha$-TH PROG were measured in distinct brain regions and in plasma of five fertile women (age: 18-42 years) and of five menopausal women (age: 59-85 years; Bixo et al., 1997). Brain concentrations of these three steroids were higher in fertile women in their luteal phase compared to the postmenopausal women and were partially depending on ovarian steroid production, indicating that serum levels determine the uptake of progestins by the brain. In spite of the correlation between blood and brain levels of PROG, it is important to note that in women with low serum concentrations of PROG, brain concentrations of PROG and of its $5 \alpha$-reduced metabolites were elevated, suggesting ac- cumulation or local formation. In addition, significant differences of steroid levels between brain regions were observed in this study, suggesting the existence of local regulatory mechanisms such as accumulation, synthesis or metabolism (Bixo et al., 1997). Postmortem concentrations of estradiol and testosterone have also been measured in 17 brain areas and serum of 6 fertile and 5 postmenopausal women. There were regional differences in the brain concentrations of both steroids, with highest levels of estradiol and testosterone in the hypothalamus, preoptic area and substantia nigra. Estradiol concentrations were significantly higher in the blood and in specific brain regions (preoptic area and substantia nigra) of fertile women when compared to postmenopausal women. Differences between fertile and postmenopausal women were not significant for testosterone. Brain levels of this steroid were found to be rather stable and did not vary with serum testosterone levels (Bixo et al., 1995).

Total corticosteroid concentrations were found to be lower in the brain than in plasma, but brain concentrations were greater than the presumed unbound fraction in plasma. All the brain regions examined contained approximately equal amounts of corticosteroids (Carroll et al., 1975).

So far, only one study has examined steroid levels by RIA in the brains of AD patients and in controls. In the control brains, levels of estradiol were 3.5-fold higher in men than in women and levels of testosterone were equivalent (age of men: $73 \pm 9$ years; age of women: $79 \pm 11$ years). There were no significant differences in brain steroid levels between control and AD patients (Twist et al., 2000).

As in the brain, very high levels of PREG have also been measured in human sciatic nerves, consistent with its local synthesis by Schwann cells. Its mean concentration (64 \pm $46 \mathrm{ng} / \mathrm{g}$ ) was about two orders of magnitude higher than levels in blood, tendons and muscle. No correlation was found with sex or age (Morfin et al., 1992).

\section{Analysis of steroids by gas chromatography/mass spectrometry (GC/MS)}

Results described in Sections 4 and 5 are based on the assay of steroids in plasma and brain tissue by RIA (Abraham, 1975; Carroll et al., 1975; Buster and Abraham, 1975). Although this method has allowed considerable progress in endocrine research, it has considerable limits with respect to specificity and sensitivity, and it is dependent on the availability of antisera. This is particularly problematic for neuroendocrine research, which requires the analysis of low levels of several steroids within individual small tissue samples. The development of very sensitive and precise analysis of steroids by GC/MS has represented a major breakthrough in this regard. In fact, because of its sensitivity in the femtomolar range, this method allows to analyze small amounts of neurosteroids in nervous tissues with great precision and reproducibility. Already introduced in 
the 1970s, analysis of steroids by GC/MS has been considerably improved since then. The work of the groups of Lieberman (Mathur et al., 1993; Prasad et al., 1985) and of Guidotti (Cheney et al., 1995) has demonstrated that the GC/MS technology can be used to measure sub-picomolar concentrations of neurosteroids in brain tissue.

More recently, the different steps of the assay have been optimized to improve its sensitivity and to allow the simultaneous measure of a large range of free and conjugated neurosteroids within distinct brain regions (Liere et al., 2000). The high sensitivity and robustness of the assay rely in part on the appropriate purification and separation of the biological extracts by solid phase extraction (SPE) on C18 columns and by high performance liquid chromatography (HPLC), allowing to isolate the different groups of steroids according to their physico-chemical characteristics (Fig. 4). The current protocol allows to detect and to quantify steroids of different polarities, ranging from hydrophilic steroid sulfates to lipophilic steroids, in a single tissue sample of a few milligrams. The separation of the different types of free steroids by HPLC also allows their optimal derivatization and the simultaneous analysis of 3-ceto as well as of 3-ceto- $\Delta 4$ mono-and polyhydroxylated steroids in a same tissue sample. That is, prior to their separation by GC and their analysis by MS, steroids are converted to halogenous or silylated derivatives. The derivatization of the steroid molecules increases their volatility, thus allowing a good chromatographic resolution, and also improves the detection of specific diagnostic ions (i.e. with high molecular mass) in the mass spectrum. The

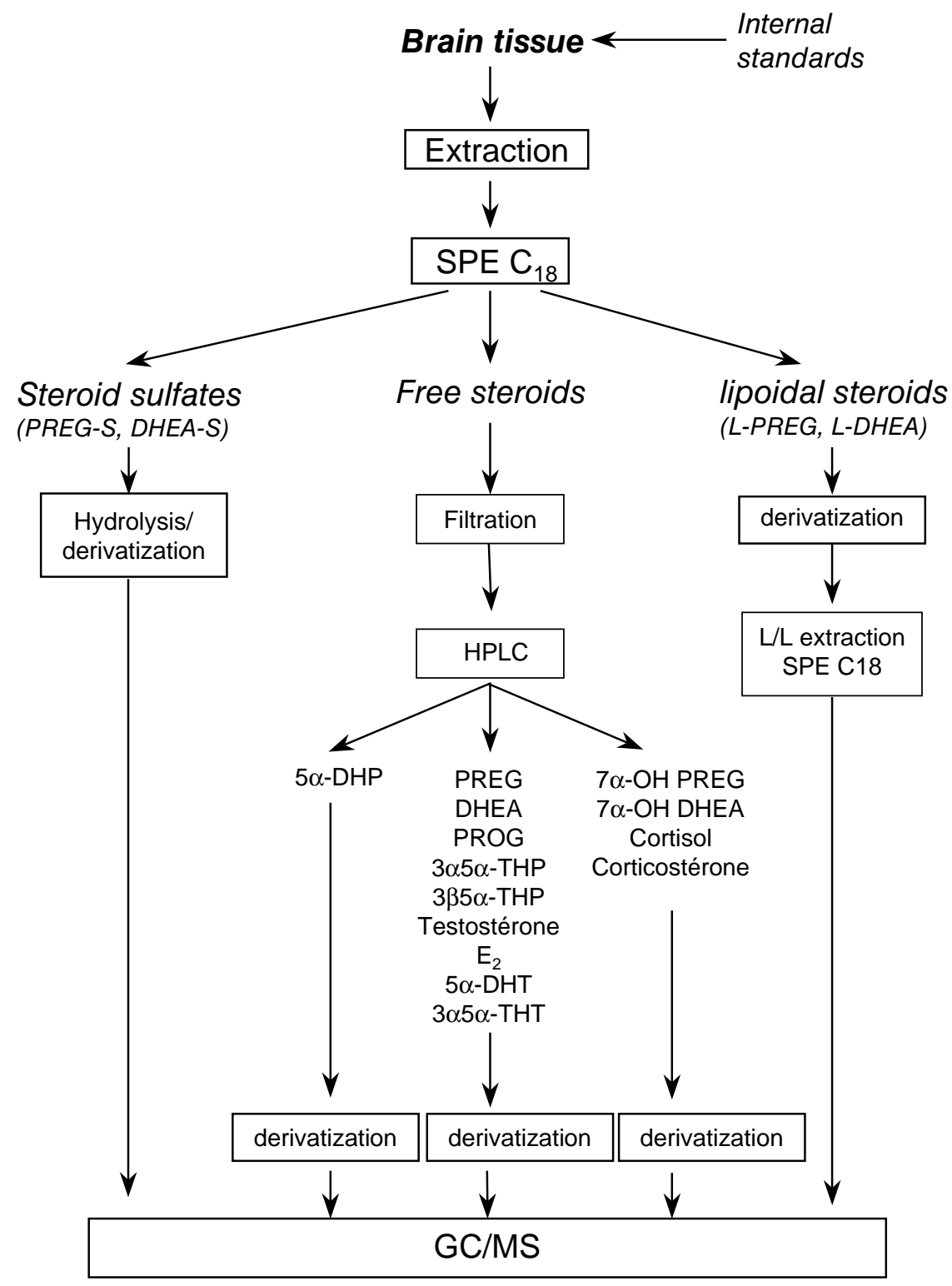

Fig. 4. Analytical procedure for the analysis of the unconjugated steroids (free steroids) and conjugated steroids (sulfates and lipoidal derivatives) in blood and brain tissue by GC/MS (SPE: solid phase extraction) For a more detailed description, see Section 6. 
derivatization reactions thus lead to increased sensitivity of the assay.

After their derivatization, steroids can be analyzed by operating the mass spectrometer either in the negative chemical ionization mode (NCI; Uzunov et al., 1996) or in the electronic impact mode (EI; Cheney et al., 1995; Liere et al., 2000). In the NCI mode, the impact of electrons $\left(\mathrm{e}^{-}, 150 \mathrm{eV}\right)$ with methane molecules $\left(\mathrm{CH}_{4}\right)$ produces low energy thermic electrons $\left(e_{\text {th }}^{-}\right)$, characterized by a kinetic energy less than $1 \mathrm{eV}$, which react with the halogenous steroid derivatives (M). This gentle ionization procedure produces little fragmentation of the steroid molecules:

$$
\begin{aligned}
& \mathrm{CH}_{4}+\mathrm{e}^{-} \rightarrow \mathrm{CH}_{4}^{\bullet+}+2 \mathrm{e}_{\text {th }}^{-} \\
& \mathrm{M}+\mathrm{e}_{\mathrm{th}}^{-} \rightarrow \mathrm{M}^{\bullet-}
\end{aligned}
$$

In the robust $\mathrm{EI}$ ionization mode, the impact of $\mathrm{e}^{-}(70 \mathrm{eV})$ with the steroid derivative $(\mathrm{M})$ produces ionized fragments $\left(\mathrm{F}^{\bullet+}\right)$, which are characteristic of the steroid molecule to be analyzed $\left(\mathrm{N}=\right.$ neutral fragments, $\mathrm{M}^{\bullet+*}=$ unstable molecular ion):

$$
\begin{aligned}
& \mathrm{M}+\mathrm{e}^{-} \rightarrow \mathrm{M}^{\bullet+*}+2 \mathrm{e}^{-} \\
& \mathrm{M}^{\bullet+*} \rightarrow \mathrm{F}^{\bullet+}+\mathrm{N}
\end{aligned}
$$

Fig. 5 illustrates the advantages of the GC/MS technology for the simultaneous analysis of a range of steroids, combining the high resolution and selectivity of the GC and the reliability of identification of the MS. The mass spectra (profiles of ion fragments) correspond indeed to molecular fingerprints of the steroid derivatives. However, not all steroid derivatives are separated by the GC and some have a similar mass spectrum. In fact, the power of the GC/MS analysis resides in the bi-dimensional analysis of the steroid derivatives by both GC and MS. This is illustrated in Fig. 5: the heptafluorobutyrate derivatives (HFB) of the $3 \alpha$ - and $3 \beta$-isomers of tetrahydroprogesterone (allopregnanolone and isoallopregnanolone) have an identical mass spectrum, but they are well separated by GC. In contrast, the HFB derivatives of PREG and PROG are not separated by GC, but their distinct mass spectra allow to identify and to quantify them separately.

\section{Analysis of neurosteroids in the brains of aged patients by GC/MS}

Whether decreased levels of steroids contribute to the development of dementia is still unclear. As described above, measures of blood levels of DHEA and DHEAS in AD patients have provided conflicting results (Leblhuber et al., 1993; Legrain et al., 1995; Yanase et al., 1996; Carlson et al., 1999; Ferrario et al., 1999; Murialdo et al., 2000). A comparative analysis of the concentrations of several neurosteroids in various brain regions between aged AD patients and aged non-demented controls has been recently reported (Weill-Engerer et al., 2002). Neurosteroids measured by
GC/MS included PREG, PREGS, DHEA, DHEAS, PROG and $3 \alpha, 5 \alpha$-TH PROG. The following six brain regions were analyzed for their steroid content: hippocampus, amygdala, frontal cortex, striatum, hypothalamus and cerebellum.

The non-demented control group comprised two women and four men (age: 75-91 years) and the AD group four women and one man (age: 81-91 years). Severe exclusion criteria were applied in this study. The postmortem delay did not exceed $24 \mathrm{~h}$, and none of the patients received steroids or benzodiazepines during the month before death. For neurological characterization, dementia was considered using the criteria of Diagnostic and Statistical Manual of Mental Disorders and criteria of AD were those proposed by the National Institute of Neurological and Communicative Disorders and Stroke-Alzheimer's Disease and Related Disorders Association. At the time of autopsy, one hemisphere of each brain was formalin-fixed for neuropathological examination, and the other one was deep-frozen until biochemical measures were performed (Weill-Engerer et al., 2002).

This study is the first to use GC/MS technology to quantify neurosteroids in the human brain and thus provides reference values. In agreement with previous studies using RIA (see Section 5), PREG was the most abundant neurosteroid in the different brain regions. Steroids found at the highest concentrations were in decreasing order PREG $>$ DHEA $>$ PROG $>$ PREGS $>$ DHEAS $\gg 3 \alpha, 5 \alpha$-TH PROG. It is important to note that levels of all these steroids, except for $3 \alpha, 5 \alpha-\mathrm{TH}$ PROG, were found to be still elevated in the brains of these old patients, and that they were much higher than previously reported blood levels (Morley et al., 1997a; Hill et al., 1999; Labrie et al., 1997a). Differences in steroid levels were observed between brain regions in non-demented patients, but not in $\mathrm{AD}$ patients. In addition to the disappearance of regional differences, there was a general trend toward lower levels of steroids in the six brain regions of $\mathrm{AD}$ patients compared with the controls (Fig. 6) (Weill-Engerer et al., 2002). A significant finding was the correlation between neurosteroid levels and two biochemical markers of $\mathrm{AD}$, namely, levels of phosphorylated tau proteins (PHF-tau) and $\beta$-amyloid peptides. PHF-tau levels were negatively correlated with DHEAS concentrations in the hypothalamus and $\beta$-amyloid peptide levels were negatively correlated with PREGS levels and to some extent with DHEAS levels in the striatum and cerebellum (Weill-Engerer et al., 2002).

\section{Age-dependent changes in the nervous system can be reversed by steroids}

Data concerning changes in brain steroid levels with age are still fragmentary and do not allow to draw definite conclusions concerning the role of steroids in the aging process of the nervous system. Obviously, more studies are urgently required. A related important question for the development of hormone therapies is whether age-related dysfunctions of the nervous system can be reversed to some extent by the 


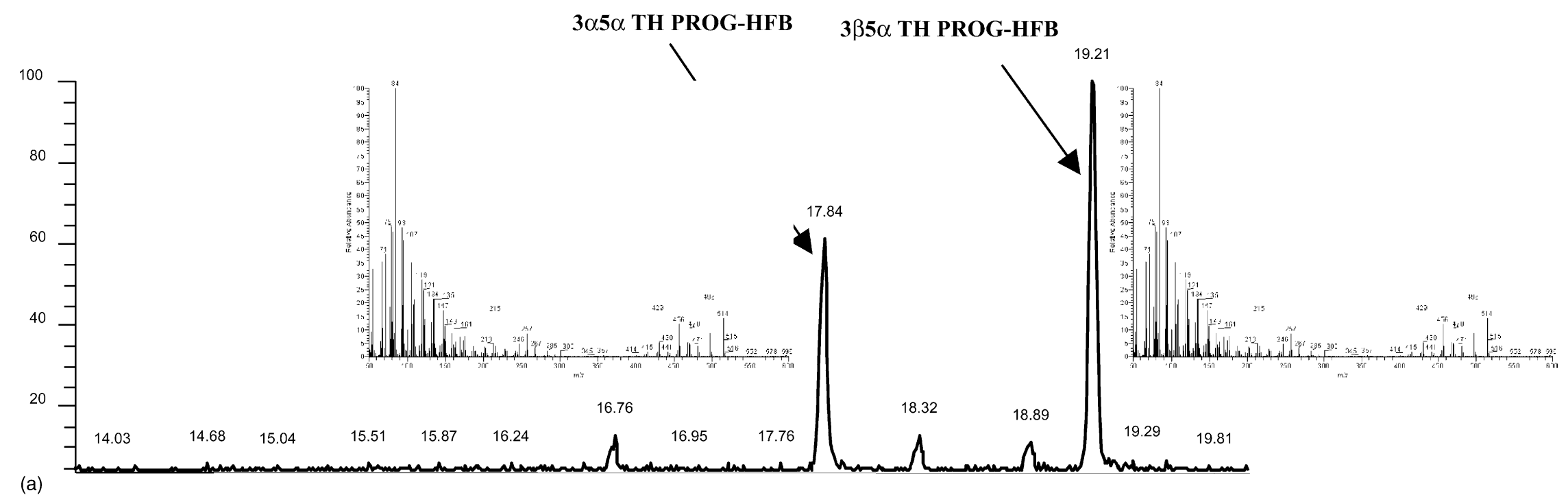

(a)

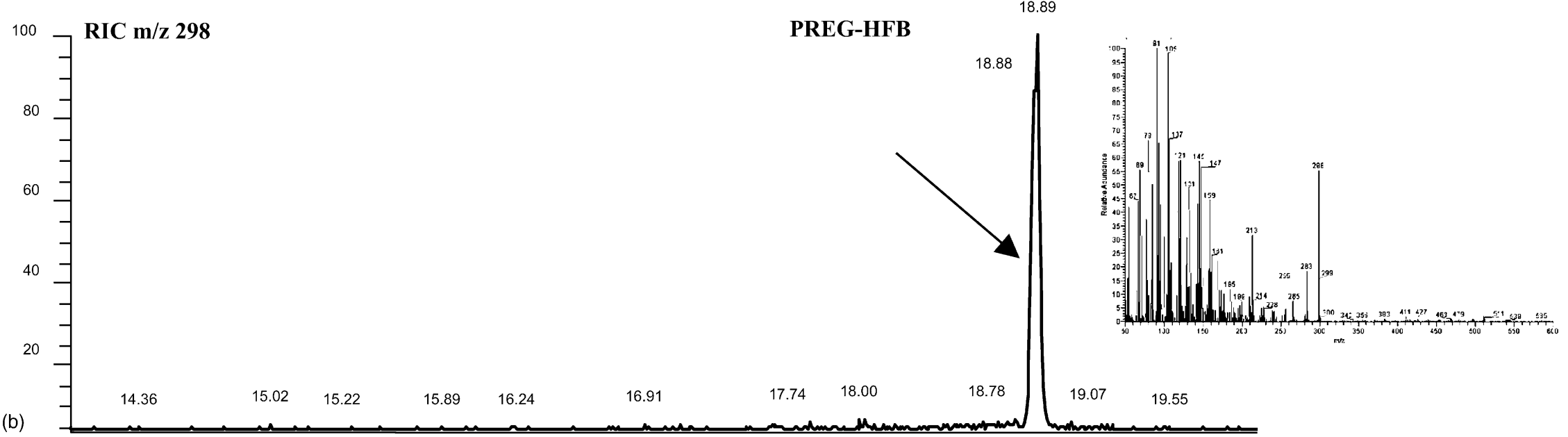

Fig. 5. The GC/MS technology combines the high resolution and selectivity of the GC and the reliability of identification of the MS. The heptafluorobutyrate derivatives (HFB) of the $3 \alpha-$ and $3 \beta$-isomers of tetrahydroprogesterone have an identical mass spectrum, but they are well separated by GC (a). The HFB derivatives of PREG (b) and PROG (c) are not separated by GC, but can be distinguished by their different mass spectra. 


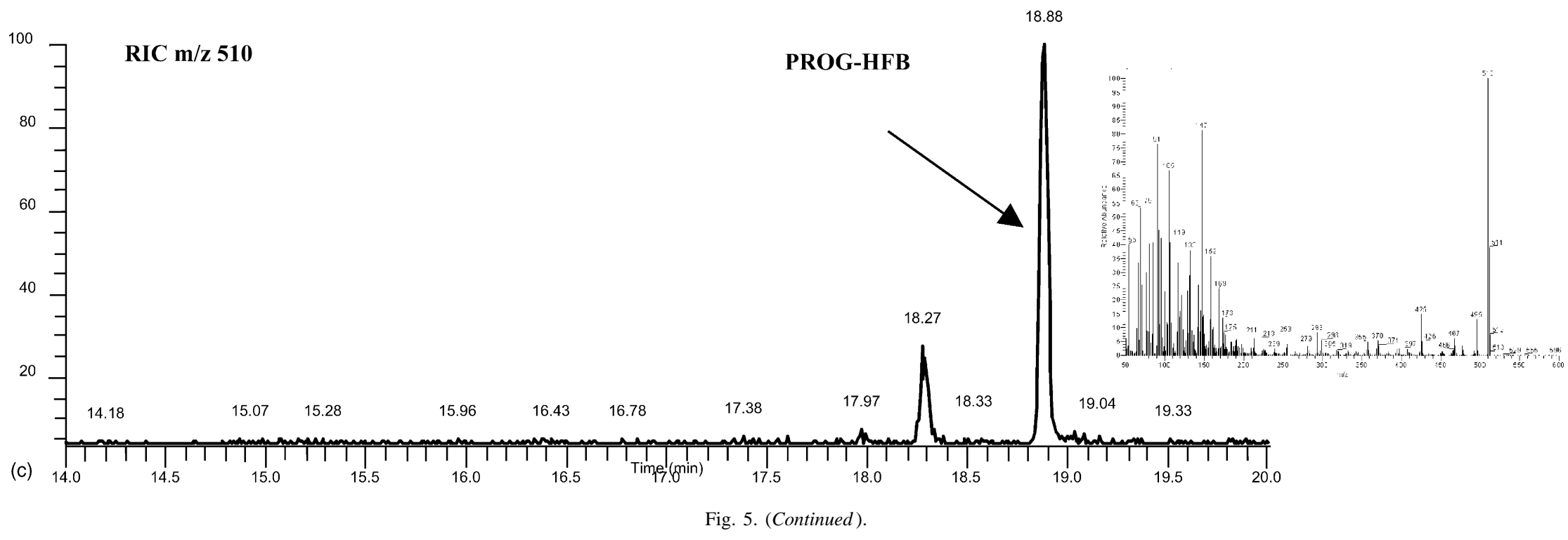



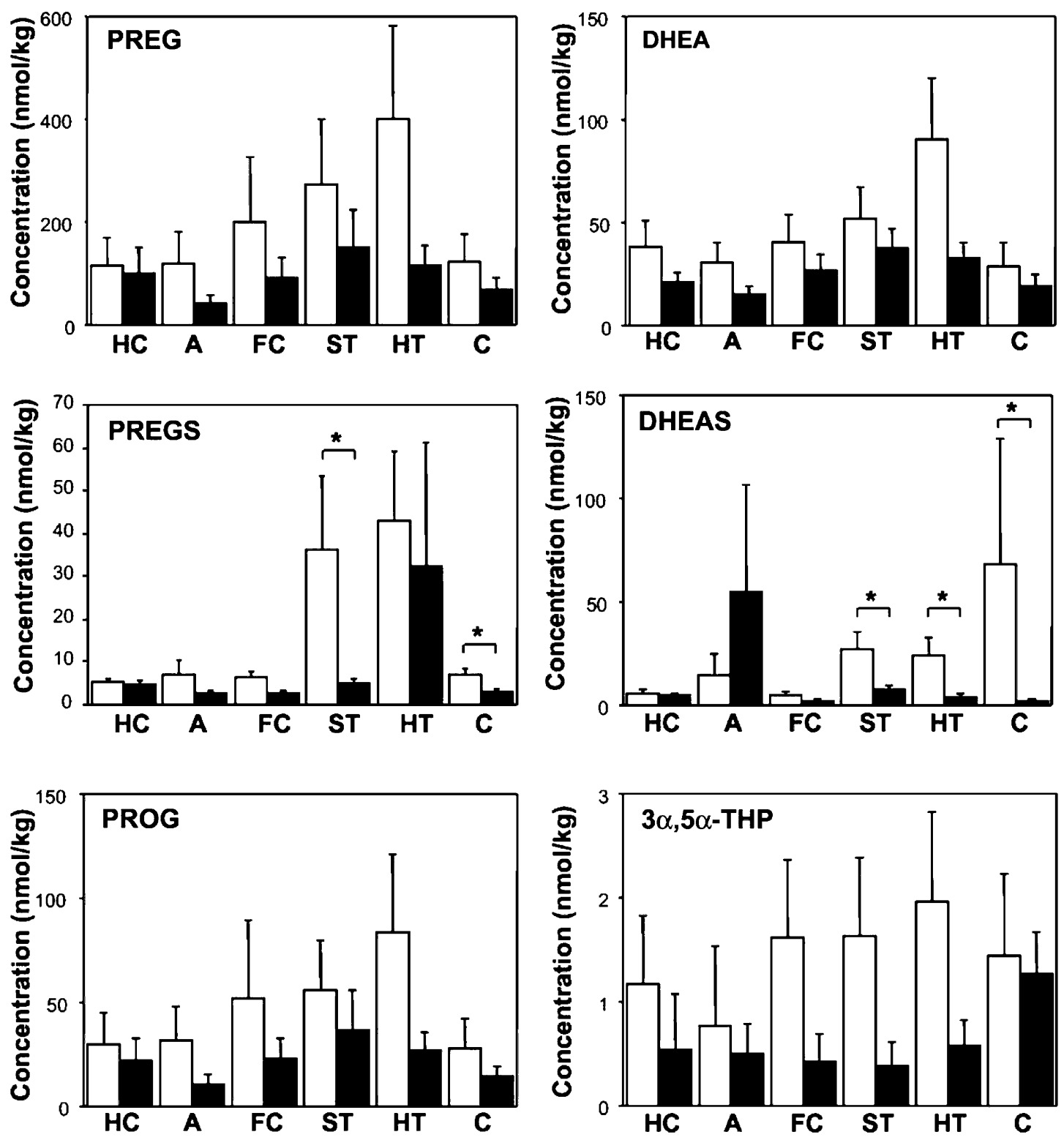

Fig. 6. Concentrations of pregnenolone (PREG), dehydroepiandrosterone (DHEA), their sulfates (PREGS and DHEAS), progesterone (PROG), and $3 \alpha, 5 \alpha$-tetrahydroprogesterone ( $3 \alpha, 5 \alpha$-TH PROG: allopregnanolone) measured in six brain regions of non-demented (white columns) and Alzheimer's (black columns) patients by GC/MS. HC: hippocampus; A: amygdala; FC: frontal cortex; ST: striatum; HT: hypothalamus; C: cerebellum $\left({ }^{*} P \leq 0.05\right.$ by Mann-Whitney test; modified from Weill-Engerer et al., 2002).

administration of steroids. We have already presented evidence that age-dependent changes of the nervous system are subtler than previously thought, and that the aging nervous system maintains some capacity for regeneration. Several recent experiments using aged animals have provided evidence that the aging nervous system indeed retains sensitivity to the trophic and protective effects of steroids and that their administration allows to improve altered nervous functions.

As already mentioned above, the spatial memory deficits of cognitively impaired aged rats ( 2 years old) can be transiently corrected by intrahippocampal injection of PREGS (Vallée et al., 1997). In young female rats (3-4 months old), the administration of low doses of estradiol attenuates ischemic brain injury. The protective actions of estradiol are most prominent in the cerebral cortex. Middle-aged rats (9-12 months old) remain equally responsive to the protective effects of estradiol after middle cerebral artery occlusion (MCAO; Wise et al., 2001; Dubal and Wise, 2001).

The prolonged treatment with progestins also allows to reverse age-related myelin abnormalities. It was first shown that the treatment of aged rats for 1 month with progestins reversed the age-dependent decline in peripheral myelin protein P0 expression, whereas the administration of androgens was without effect (Melcangi et al., 1998a,b). The prolonged administration of progestins 
(PROG, $5 \alpha$-dihydroprogesterone or $3 \alpha, 5 \alpha$-TH PROG) not only counteracted the drop in P0 mRNA, it also allowed to improve age-related structural abnormalities of the peripheral myelin sheaths. Androgens were again found to be inefficient (Azcoitia et al., 2003). In the CNS of old male rats, administration of PROG for 5 weeks promoted the slow remyelination of axons by oligodendrocytes after toxin-induced demyelination (Ibanez et al., in press).

\section{Hormone replacement therapy in humans}

To compensate for the age-dependent decline in circulating steroid levels, hormone replacement therapies are now commonly used for promoting successful aging (Lamberts et al., 1997). As estradiol has important functions in bones, in the cardiovascular system and in the nervous system, estrogen replacement therapy in postmenopausal women has elicited particular interest (Wise et al., 1999). A now standard practice is to give estrogens together with progestins to reduce the risk of endometrial cancer (Sitruk-Ware, 2000).

With respect to the nervous system, many studies have suggested that ERT may improve cognitive functions, may protect against age-associated memory decline and may delay the onset and decrease the risk of AD (Phillips and Sherwin, 1992; Brenner et al., 1994; Paganini-Hill and Henderson, 1994, 1996; Kawas et al., 1997; Jacobs et al., 1998; Resnick et al., 1998; Costa et al., 1999; Smith et al., 2001; Fillenbaum et al., 2001; Tang et al., 1996; Yaffe et al., 1998b). Estrogens may not only protect against the onset of $\mathrm{AD}$, they may also maintain cognitive functions in women who already have AD (Henderson et al., 1994; Asthana et al., 1999, 2001). However, some studies have questioned the positive impact of ERT on the risk of AD or on cognitive decline in women with AD (Brenner et al., 1994; Henderson et al., 2000; Mulnard et al., 2000; Wang et al., 2000).

A major controversy has been launched during the past few months concerning the use of HRT in postmenopausal women. Five studies recently published by the Women's Health Initiative (WHI), all based on the same large randomized and controlled trial, have indeed seriously questioned the favorable effects of estrogen plus progestin therapy in postmenopausal women and have pointed to the risks (Women's Health Initiative Investigators, 2002, 2003a,b,c,d). This huge trial investigated the effects of the treatment with $0.625 \mathrm{mg}$ per day of conjugated equine estrogens plus $2.5 \mathrm{mg}$ per day of the synthetic progestin medroxyprogesterone acetate (E + MPA) on the incidence of coronary heart disease, breast cancer, stroke, global cognitive functions, MCI and dementia in postmenopausal women with an intact uterus aged 50-79 years ( 8102 women were enrolled in the placebo group and 8506 women in the E + MPA group). The initially planned duration of the trial was 8.5 years, but it was prematurely stopped after only 5.2 years, because the overall health risks of the hormone treatment outweighed the benefits (a parallel trial of estrogen alone in women with hysterectomy is still in progress). A first study based on the WHI trial reported that the rate of coronary heart disease was slightly increased in $\mathrm{E}+\mathrm{MPA}$ women (3.7/1000 person-years) when compared to the placebo group (3/1000 person-years; Women's Health Initiative Investigators, 2002). There was also a modest increase in invasive breast cancer in E + MPA women (3.8/1000 person-years versus $3 / 1000$ person-years). A second study of the WHI trial reported an increased risk of ischemic stroke in healthy postmenopausal women (Women's Health Initiative Investigators, 2003c). After an average of 5.6 years of follow-up, there were 151 strokes in the $\mathrm{E}+$ MPA group and 107 strokes in the placebo group. The risk was similar for the younger women participating in the trial (50-59 years old). The third WHI study reported that estrogen plus progestin did not improve cognitive functions in postmenopausal women 65 years or older, but that there was a small risk for cognitive decline when compared with placebo (Women's Health Initiative Investigators, 2003b). The fourth study showed that in postmenopausal women aged 65 years or older, daily estrogen plus progestin after an average 4 years of follow-up did not prevent MCI but increased the risk of dementia, although the number of women with dementia was small $(4.5 / 1000$ person-years versus 2.2/1000 person-years; Women's Health Initiative Investigators, 2003a). This increased risk in dementia may have resulted from the cardiovascular effects of the steroids, as vascular diseases often coexist with dementia (Snowdon et al., 1997; Yaffe, 2003).

Finally, a fifth study based on the WHI trial reported that estrogen plus progestin had no significant effects on general health, vitality, mental health, depressive symptoms or sexual satisfaction. After 3 years of trial, no meaningful benefits in terms of quality of life were observed (Women's Health Initiative Investigators, 2003d). Because of the lack of favorable effects of the HRT and of the significantly increased risk, the WHI recommended not to initiate or to continue estrogen plus MPA replacement therapy in postmenopausal women with an intact uterus for the prevention of coronary heart disease, stroke and dementia. According to their recommendations, hormone therapy should only be prescribed for temporary use to treat menopausal symptoms (Yaffe, 2003).

What may explain the discrepancies between the outcome of this large trial and the wealth of animal studies and the many previous clinical trials that supported beneficial and protective effects of estrogens on the cardiovascular system and on cognitive functions? Many questions remain open after this trial with respect to the timing of the HRT, the doses of steroids, the mode of their administration and the steroid compounds used. Thus, the WHI study did not address the effects of short-term HRT and of prolonged HRT starting early during the perimenopausal period. The trial also did not address the benefits of HRT for the treatment of menopausal symptoms such as hot flashes. It is also important to note that the absolute risks associated with the daily estrogen-MPA 
therapy were rather small and that the all-cause mortality was not affected during the trial (Women's Health Initiative Investigators, 2002).

An important matter for discussion is the use of a relatively high dose of conjugated equine estrogen in combination with the synthetic progestin MPA in the WHI trial. With respect to the latter, controversy has been raised over the role of progestins in HRT and their risks. There are in fact several classes of progestins, which differ by their pharmacological properties. Natural PROG and some of its derivatives such as the 19-norprogesterones (nestorone, nonmegestrol acetate, trimegestone) do not have androgenic side effects. Other newly synthesized progestins have partial antiandrogenic properties, such as drospirenone, which is a derivative of spironolactone and binds to the mineralocorticoid receptor (Henzl and Edwards, 2000; Sitruk-Ware, 2002). Some of the frequently used progestins bind to the androgen receptor and have high androgenic potency and eventually may attenuate the beneficial actions of estrogens or exert deleterious effects, which are not necessarily shared by progestins devoid of androgenic properties.

MPA, which has been used in the WHI trial and is one of the clinically most used progestins, has both androgenic and synandrogenic properties (Bullock et al., 1978; Sitruk-Ware, 2002). MPA has also been reported to possess glucocorticoid activity (Ishida et al., 2002) and to inhibit the beneficial effects of estrogen (Wakatsuki et al., 2001). In addition, prolonged MPA treatment affects other endocrine responses in postmenopausal women: it decreases LH and FSH and increases IGF-1 levels (Saaresranta et al., 2002). These interactions of MPA with other hormone signaling systems may account for some of its side effects on the cardiovascular and nervous systems that are listed further.

Concerning the cardiovascular system, a study in rhesus monkeys has shown that estradiol plus PROG protects against coronary vasospasm, but that estradiol plus MPA failed to protect, suggesting that MPA may increase the risk of this affection (Miyagawa et al., 1997). Other studies confirm that MPA blunts the beneficial effects of estrogen and that this synthetic progestin does not exert the same effects as natural PROG. In postmenopausal women, MPA has been shown to inhibit the beneficial effects of estrogen on endothelium-dependent vasodilatation (Wakatsuki et al., 2001; Kawano et al., 2001). Natural PROG, but not MPA, enhanced the beneficial effects of estrogen on exercise-induced myocardial ischemia (Rosano et al., 2000). MPA, but not micronized PROG, blunted the beneficial association between estrogen and high-density lipoprotein (HDL) cholesterol (Barrett-Connor et al., 1997). However, the increase in cerebrovascular endothelial nitric oxide synthase (eNOS) activity by estradiol, which corresponds to one of its vasoprotective mechanisms of action (Chen et al., 1999), was not prevented by the concurrent administration of MPA (McNeill et al., 2002).

With respect to the nervous system, estradiol, PROG or 19-norprogesterone, alone or in combination, protect hip- pocampal neurons against glutamate cytotoxicity. Not only was MPA ineffective in protecting the neurons, this compound also inhibited the neuroprotective effects of estradiol when coadministered. In agreement with this observation, estradiol, PROG or 19-norprogesterone all increased expression of the antiapoptotic protein B-cell leukemia/lymphoma (Bcl-2), whereas MPA blocked estrogen-induced Bcl-2 expression (Nilsen and Brinton, 2002). Continuous MPA users more likely reported depressive symptoms than controls (Civic et al., 2000; Saaresranta et al., 2002). MPA also opposes the beneficial association between estrogen and cognitive changes (Rice et al., 2000). However, a recent study has reported beneficial effects of MPA on mood in postmenopausal women, and in particular in those with a history of premenstrual syndrome (Bjorn et al., 2002).

The decline in testosterone levels in men with age is very progressive and shows great inter-individual variability. The clinical manifestations of androgen deficiency in men may include decreased muscle mass and strength, increased fat mass, decreased hematocrit, decreased libido, erectile dysfunction, infertility, osteoporosis, anxiety, irritability, insomnia, depressed mood. Androgen replacement therapy with testosterone has been proposed to be a safe and effective treatment for testosterone deficiency (Sternbach, 1998; Winters, 1999). However, there are only a limited number of testosterone replacement studies with sometimes conflicting results (Sih et al., 1997; Tenover, 1992; Snyder et al., 1999a,b). In particular, in hypogonadal men, testosterone therapy may offer benefit, but long-term studies on its efficacy and safety are still lacking. One study has reported that testosterone replacement therapy may improve depression and promote verbal and spatial memory in aging men (Sternbach, 1998). Supplementation of healthy older men with testosterone for 3 months enhanced their spatial cognition, but did not significantly influence verbal and visual memory, cognitive flexibility and mood (Janowsky et al., 1994).

As testosterone also significantly declines after menopause, restoring its levels may also be of benefit for women and improve their quality of life with respect to libido, sense of well-being, protection of cardiovascular health and prevention of osteoporosis (Rako, 1998). Inclusion of testosterone in postmenopausal HRT is not uncommon, and androgen therapy has been shown to alleviate several symptoms in postmenopausal women and to improve their quality of life. Whether the therapeutic effects of testosterone replacement are mediated by testosterone itself, its $5 \alpha$-reduced metabolites or are a consequence of its aromatization to estrogen is unknown (Davis, 1999).

Placebo-controlled studies have also documented beneficial effects of the oral administration of DHEA in the elderly. Daily treatment with DHEA of men and women of advancing age resulted in an increase in perceived physical and psychological well-being, increased lean body mass in both sexes and increased muscle strength in men (Morales et al., 1994, 1998). In a randomized, double-blind, 
placebo-controlled trial among 140 elderly men and 140 elderly women (60-79 years old), 50 mg of DHEA given daily for 1 year reestablished circulating levels of DHEAS and slightly increased levels of testosterone and estradiol. The treatment led to improved bone turnover and skin status, especially in women (Baulieu et al., 2000).

However, in spite of the numerous animal studies documenting beneficial effects of DHEA or DHEAS on nervous functions and memory, most human trials have failed to demonstrate an effect of DHEA on cognitive performance in the elderly (Arlt et al., 2000; Wolf et al., 1997), except for one study showing antidepressant and cognition-enhancing effects in major depression (Wolkowitz et al., 1995).

\section{Conclusions and perspectives}

In the developed countries, the greater life expectancy and the rapidly aging populations have increased the need for health promotion in the elderly. In particular, the increasing incidence and prevalence of cognitive impairment and dementia, which will become one of the main causes of disability without medical progress, is a major public health issue. A delay of their onset would already markedly reduce their prevalence and would thus have an enormous impact on health care expenditures and on the well-being of the elderly.

Preclinical research using a variety of animal models and cell culture systems has provided promising results. They indicate that the administration of steroids that support important neuronal and glial functions may protect the aging nervous system, prevent the development of neurodegenerative diseases and even reverse to some extent age-dependent neuromorphological and cognitive changes. The main findings reported in this review can be summarized as follows: (1) during normal aging, there is no massive loss of neurons in the brain; (2) the aging nervous system maintains capacity for regeneration; (3) steroids have pleiotropic effects in the nervous system, and they play important roles in the viability of neurons, the maintenance and repair of myelin sheaths and in cognitive processes, in particular in learning and memory; (4) steroids present in nervous tissues originate from the endocrine glands and from local synthesis (neurosteroids); (5) the aging nervous system remains sensitive to the protective effects of steroids; and (6) age-dependent cognitive dysfunctions and alterations of the myelin sheaths can be partially reversed by steroid administration. Together, these findings strongly suggest that the use of steroids provides interesting therapeutical opportunities for promoting successful aging.

In contrast to the wealth of preclinical findings reporting beneficial effects of steroids on the nervous system, even in aged animals, the results of clinical studies are not conclusive. There is still no clear evidence for beneficial effects of HRT on mood and cognitive functions in the elderly. After the initial euphoria prompted by studies suggesting that ERT in postmenopausal women may protect against the on- set of $\mathrm{AD}$ and even improve cognitive functions in women who already suffer from the disease, a series of studies have questioned these beneficial effects of estrogen. Moreover, recent results from a very large trial conducted by the WHI have not only questioned the benefits of estrogen plus progestin therapy in postmenopausal women, but they have also pointed to the risks. One reason for the outcome of this trial may be related to the conditions of the treatment, and in particular to the use of the synthetic progestin MPA, which has been shown to have androgenic properties and to antagonize beneficial effects of estrogens on the cardiovascular and nervous systems. Whether "pure" progestins, which do not interfere with other steroid receptor systems, may exert beneficial effects on the aging nervous system as strongly suggested by animal studies is so far unknown. Concerning two other steroids that, based on preclinical data, can be expected to play a significant role in the aging nervous system, namely testosterone and DHEA, there is so far only limited information.

The recent controversy concerning the potential benefits and risks of steroid therapies in the elderly show that HRT, although widely used, is still in its infancy. More controlled clinical trials are urgently needed to evaluate the benefits and risks of steroid treatments in the elderly. More information is required concerning age-dependent changes of steroid levels in the nervous system of normally aging and demented patients of both sexes.

There is also need for the development of safer steroid compounds with more selective and efficient actions on specific nervous functions. Selective estrogen and PR modulators (SERMs and SPRMs), which have both agonist and antagonist activities depending upon the site of their action (mixed agonists/antagonists), offer interesting therapeutical possibilities for the aging nervous system and may have advantages over current HRT because of their selective actions and pharmacological characteristics. A variety of SERMs have been developed recently with beneficial effects on neurons and on cognitive functions (Barham, 2003; Chwalisz et al., 2002; Dhandapani and Brann, 2002; Krishnan et al., 2000; Littleton et al., 2002; Roe et al., 2000; Whitaker, 2001; Yaffe, 2001).

Steroid enantiomers also offer interesting perspectives for the treatment of age-dependent cognitive impairment or neurodegenerative diseases. These are mirror-symmetric, non-superimposable images of the molecules, with identical physical properties (except for the different rotation of polarized light; Covey et al., 2000). The synthetic (-)-enantiomer of PREGS was 10 times more potent in activating memory functions than natural (+)-PREGS. This effect showed enantiomeric selectivity: in contrast to (+)-PREGS, the promnesic effects of (-)-PREGS could not be blocked by a selective NMDA receptor antagonist (Akwa et al., 2001).

From the concept of neurosteroids derives another therapeutical strategy: the use of pharmaceutical agents that increase the synthesis of endogenous neurosteroids within the nervous system. This approach is so far hampered by 
the lack of knowledge concerning the regulation of the biosynthetic pathways of neurosteroids. Ligands of the MBR have been shown to increase the synthesis of neurosteroids in cultured glioma cells (Papadopoulos et al., 1992) and in the brain (Korneyev et al., 1993; Romeo et al., 1993; Bitran et al., 2000). The possibility to increase the synthesis of neuroactive steroids has stimulated recent efforts to develop new more selective and efficient MBR ligands. Thus, derivatives of 2-phenyl-imidazol[1,2]pyrimidine bind MBR ligands with great affinity and selectivity, and when injected intraperitoneally, they significantly increase brain neurosteroid levels in castrated and adrenalectomized rats, in agreement with a stimulatory effect on brain neurosteroidogenesis (Serra et al., 1999; Trapani et al., 1999). Among the pharmaceutical agents that have been recently developed to influence neurosteroid levels in the brain are the steroid sulfatase inhibitors. By increasing the accumulation of neuroactive PREGS and DHEAS in the brain, they have promnesic effects and reverse pharmacologically-induced amnesia (Johnson et al., 1997; Li et al., 1995, 1997; Rhodes et al., 1997).

Steroid therapy may become an important component of preventive strategies against age-dependent cognitive dysfunctions, ranging from MCI to dementing diseases such as AD. The development of safer and more selective steroid receptor ligands, the targeting of alternative steroid signaling pathways and the stimulation of neurosteroid synthesis offer interesting possibilities for preventing and treating age-dependent changes in nervous functions. However, it is unlikely that steroids are sufficient and that they can substitute for a healthful lifestyle, including intellectual activity, exercise and diet, but they may make a valuable contribution to successful aging. During normal aging, steroids may rather work as adjuvants by increasing the well-being of the elderly and by stimulating brain mechanisms involved in cognitive functions and motivation. Steroid replacement therapy may be particularly effective in preserving vital nervous functions in the case of severe hormone deficiencies.

\section{Acknowledgements}

This study has been supported by a grant from the Commission of the European Communities, specific RTD programme "Quality of Life and Management of Living Resources", QLK6-CT-2000-00179. The support given by the Myelin Project (USA) and Projet Myéline (France) to the laboratories of MS and RF is also gratefully acknowledged.

\section{References}

Abraham, G.E., 1975. Radioimmunoassay of steroids in biological fluids. J. Steroid Biochem. 6, 261-270.

Akwa, Y., Ladurelle, N., Covey, D.F., Baulieu, E.E., 2001. The synthetic enantiomer of pregnenolone sulfate is very active on memory in rats and mice, even more so than its physiological neurosteroid counterpart: distinct mechanisms? Proc. Natl. Acad. Sci. U.S.A. 98, 14033-14037.

Amouyel, P., 2002. Genetic susceptibility to ageing-associated diseases. C. R. Biol. 325, 741-745.

Arlt, W., Callies, F., Allolio, B., 2000. DHEA replacement in women with adrenal insufficiency: pharmacokinetics, bioconversion and clinical effects on well-being, sexuality and cognition. Endocr. Res. 26, 505511

Asthana, S., Craft, S., Baker, L.D., Raskind, M.A., Birnbaum, R.S., Lofgreen, C.P., Veith, R.C., Plymate, S.R., 1999. Cognitive and neuroendocrine response to transdermal estrogen in postmenopausal women with Alzheimer's disease: results of a placebo-controlled, double-blind, pilot study. Psychoneuroendocrinology 24, 657-677.

Asthana, S., Baker, L.D., Craft, S., Stanczyk, F.Z., Veith, R.C., Raskind, M.A., Plymate, S.R., 2001. High-dose estradiol improves cognition for women with $\mathrm{AD}$ : results of a randomized study. Neurology 57 , $605-612$.

Azcoitia, I., Leonelli, E., Magnaghi, V., Veiga, S., Garcia-Segura, L.M., Melcangi, R.C., 2003. Progesterone and its derivatives dihydroprogesterone and tetrahydroprogesterone reduce myelin fiber morphological abnormalities and myelin fiber loss in the sciatic nerve of aged rats. Neurobiol. Aging 24, 853-860.

Balthazart, J., Ball, G.F., 1998. New insights into the regulation and function of brain estrogen synthase (aromatase). Trends Neurosci. 21, 243-249.

Barham, M., 2003. Selective estrogen-receptor modulators. N. Engl. J. Med. 348, 2259.

Barrett-Connor, E., Edelstein, S.L., 1994. A prospective study of dehydroepiandrosterone sulfate and cognitive function in an older population: the Rancho Bernardo Study. J. Am. Geriatr. Soc. 42, 420423.

Barrett-Connor, E., Slone, S., Greendale, G., Kritz-Silverstein, D., Espeland, M., Johnson, S.R., Waclawiw, M., Fineberg, S.E., 1997. The Postmenopausal Estrogen/Progestin Interventions Study: primary outcomes in adherent women. Maturitas 27, 261-274.

Baulieu, E.E., 1991. Neurosteroids: a new function in the brain. Biol. Cell 71, 3-10.

Baulieu, E.E., 1997. Neurosteroids: of the nervous system, by the nervous system, for the nervous system. Recent Prog. Horm. Res. 52, 1-32.

Baulieu, E.E., Robel, P., Schumacher, M., 1999. Neurosteroids. A New Regulatory Function in the Nervous System. Humana Press, Totowa, NJ.

Baulieu, E.E., Thomas, G., Legrain, S., Lahlou, N., Roger, M., Debuire, B., Faucounau, V., Girard, L., Hervy, M.P., Latour, F., Leaud, M.C., Mokrane, A., Pitti-Ferrandi, H., Trivalle, C., de Lacharrière, O., Nouveau, S., Rakoto-Arison, B., Souberbielle, J.C., Raison, J., Le Bouc, Y., Raynaud, A., Girerd, X., Forette, F., 2000. Dehydroepiandrosterone (DHEA), DHEA sulfate, and aging: contribution of the DHEAge Study to a sociobiomedical issue. Proc. Natl. Acad. Sci. U.S.A. 97, 42794284.

Baulieu, E.E., Robel, P., Schumacher, M., 2001. Neurosteroids: beginning of the story. Int. Rev. Neurobiol. 46, 1-32.

Behl, C., Skutella, T., Lezoualc'h, F., Post, A., Widmann, M., Newton, C.J., Holsboer, F., 1997. Neuroprotection against oxidative stress by estrogens: structure-activity relationship. Mol. Pharmacol. 51, 535541

Belanger, A., Candas, B., DuPont, A., Cusan, L., Diamond, P., Gomez, J.L., Labrie, F., 1994. Changes in serum concentrations of conjugated and unconjugated steroids in 40-80-year-old men. J. Clin. Endocrinol. Metab. 79, 1086-1090.

Bellino, F.L., Daynes, R.A., Hornsby, P.J., Lavrin, D.H., Nestler, J.E., 1995. Dehydroepiandrosterone (DHEA) and Aging, vol. 774. New York Academy of Sciences, New York.

Beyenburg, S., Stoffel-Wagner, B., Watzka, M., Blumcke, I., Bauer, J., Schramm, J., Bidlingmaier, F., Elger, C.E., 1999. Expression of cytochrome P450scc mRNA in the hippocampus of patients with temporal lobe epilepsy. Neuroreport 10, 3067-3070. 
Beyenburg, S., Watzka, M., Blumcke, I., Schramm, J., Bidlingmaier, F., Elger, C.E., Stoffel-Wagner, B., 2000. Expression of mRNAs encoding for 17beta-hydroxisteroid dehydrogenase isozymes 1, 2, 3 and 4 in epileptic human hippocampus. Epilepsy Res. 41, 83-91.

Beyenburg, S., Watzka, M., Clusmann, H., Blumcke, I., Bidlingmaier, F., Elger, C.E., Stoffel-Wagner, B., 2001. Messenger RNA of steroid 21-hydroxylase (CYP21) is expressed in the human hippocampus. Neurosci. Lett. 308, 111-114.

Bitran, D., Foley, M., Audette, D., Leslie, N., Frye, C.A., 2000. Activation of peripheral mitochondrial benzodiazepine receptors in the hippocampus stimulates allopregnanolone synthesis and produces anxiolytic-like effects in the rat. Psychopharmacology 151, 64-71.

Bixo, M., Backstrom, T., Winblad, B., Andersson, A., 1995. Estradiol and testosterone in specific regions of the human female brain in different endocrine states. J. Steroid Biochem. Mol. Biol. 55, 297-303.

Bixo, M., Andersson, A., Winblad, B., Purdy, R.H., Bäckström, T., 1997. Progesterone, 5alpha-pregnane-320-dione and 3alpha-hydroxy-5alphapregnane-20-one in specific regions of the human female brain in different endocrine states. Brain Res. 764, 173-178.

Bjorn, I., Bixo, M., Nojd, K.S., Collberg, P., Nyberg, S., Sundstrom, P., Backstrom, T., 2002. The impact of different doses of medroxyprogesterone acetate on mood symptoms in sequential hormonal therapy. Gynecol. Endocrinol. 16, 1-8.

Bologa, L., Sharma, J., Roberts, E., 1987. Dehydroepiandrosterone and its sulfated derivative reduce neuronal death and enhance astrocytic differentiation in brain cell cultures. J. Neurosci. Res. 17, 225-234.

Brenner, D.E., Kukull, W.A., Stergachis, A., van Belle, G., Bowen, J.D., McCormick, W.C., Teri, L., Larson, E.B., 1994. Postmenopausal estrogen replacement therapy and the risk of Alzheimer's disease: a population-based case-control study. Am. J. Epidemiol. 140, 262-267.

Brown, R.C., Cascio, C., Papadopoulos, V., 2000. Pathways of neurosteroid biosynthesis in cell lines from human brain: regulation of dehydroepiandrosterone formation by oxidative stress and beta-amyloid peptide. J. Neurochem. 74, 847-859.

Bullock, L.P., Bardin, C.W., Sherman, M.R., 1978. Androgenic, antiandrogenic, and synandrogenic actions of progestins: role of steric and allosteric interactions with androgen receptors. Endocrinology 103, $1768-1782$.

Burger, H.G., Dudley, E.C., Robertson, D.M., Dennerstein, L., 2002. Hormonal changes in the menopause transition. Recent Prog. Horm. Res. 57, 257-275.

Buster, J.E., Abraham, G.E., 1975. The applications of steroid hormone radioimmunoassays to clinical obstetrics. Obstet. Gynecol. 46, 489499.

Callier, S., Morissette, M., Grandbois, M., Di Paolo, T., 2000. Stereospecific prevention by 17beta-estradiol of MPTP-induced dopamine depletion in mice. Synapse 37, 245-251.

Cardona-Gomez, G.P., Mendez, P., Doncarlos, L.L., Azcoitia, I., Garcia-Segura, L.M., 2001. Interactions of estrogens and insulin-like growth factor-I in the brain: implications for neuroprotection. Brain Res. Rev. 37, 320-334.

Cardounel, A., Regelson, W., Kalimi, M., 1999. Dehydroepiandrosterone protects hippocampal neurons against neurotoxin-induced cell death: mechanism of action. Soc. Exp. Biol. Med. 222, 145-149.

Carlson, L.E., Sherwin, B.B., 1999. Relationships among cortisol (CRT), dehydroepiandrosterone-sulfate (DHEAS), and memory in a longitudinal study of healthy elderly men and women. Neurobiol. Aging 20, 315-324.

Carlson, J.L., Martin, P.M., de Launoit, Y., 1994. Characterization of 17beta-hydroxysteroid dehydrogenase activity and mRNA abundance in human meningioma tumors. Neuroendocrinology 60, 445-451.

Carlson, L.E., Sherwin, B.B., Chertkow, M.H., 1999. Relationship between dehydroepiandrosterone sulfate (DHEAS) and cortisol (CRT) plasma levels and everyday memory in Alzheimer's disease patients compared to healthy controls. Horm. Behav. 35, 254-263.

Carroll, B.J., Heath, B., Jarrett, D.B., 1975. Corticosteroids in brain tissue. Endocrinology 97, 290-300.
Cascio, C., Brown, R.C., Liu, Y., Han, Z., Hales, D.B., Papadopoulos, V., 2000. Pathways of dehydroepiandrosterone formation in rat brain glia. J. Steroid Biochem. Mol. Biol. 75, 177-186.

Chan, J.R., Phillips, L.J., Glaser, M., 1998. Glucocorticoids and progestins signal the initiation and enhance the rate of myelin formation. Proc. Natl. Acad. Sci. U.S.A. 95, 10459-10464.

Chen, Z., Yuhanna, I.S., Galcheva-Gargova, Z., Karas, R.H., Mendelsohn, M.E., Shaul, P.W., 1999. Estrogen receptor alpha mediates the nongenomic activation of endothelial nitric oxide synthase by estrogen. J. Clin. Invest. 103, 401-406 (published erratum appeared in 1999 in J. Clin. Invest. 103 (9), 1363).

Cheney, D.L., Uzunov, D., Costa, E., Guidotti, A., 1995. Gas chromatographic-mass fragmentographic quantitation of 3alpha-hydroxy-5alphapregnan-20-one (allopregnanolone) and its precursors in blood and brain of adrenalectomized and castrated rats. J. Neurosci. 15, 46414650.

Chwalisz, K., Garg, R., Brenner, R.M., Schubert, G., Elger, W., 2002. Selective progesterone receptor modulators (SPRMs): a novel therapeutic concept in endometriosis. Ann. N. Y. Acad. Sci. 955, $373-$ 388.

Civic, D., Scholes, D., Ichikawa, L., Lacroix, A.Z., Yoshida, C.K., Ott, S.M., Barlow, W.E., 2000. Depressive symptoms in users and non-users of depot medroxyprogesterone acetate. Contraception 61, 385-390.

Compagnone, N.A., Mellon, S.H., 1998. Dehydroepiandrosterone: a potential signalling molecule for neocortical organization during development (see comments). Proc. Natl. Acad. Sci. U.S.A. 95, 46784683.

Corpéchot, C., Robel, P., Lachapelle, F., Baumann, N., Axelson, M., Sjovall, J., Baulieu, E.E., 1981. Dehydroepiandrosterone libre et sulfo-conjugee dans le cerveau de souris dysmyeliniques. C. R. Acad. Sci. Paris 292, 231-234.

Costa, M.M., Reus, V.I., Wolkowitz, O.M., Manfredi, F., Lieberman, M., 1999. Estrogen replacement therapy and cognitive decline in memory-impaired post-menopausal women. Biol. Psychiatry 46, 182 188.

Covey, D.F., Nathan, D., Kalkbrenner, M., Nilsson, K.R., Hu, Y., Zorumski, C.F., Evers, A.S., 2000. Enantioselectivity of pregnanoloneinduced gamma-aminobutyric $\operatorname{acid}(\mathrm{A})$ receptor modulation and anesthesia. J. Pharmacol. Exp. Ther. 293, 1009-1016.

Culty, M., Li, H., Boujrad, N., Amri, H., Vidic, B., Bernassau, J.M., Reversat, J.L., Papadopoulos, V., 1999. In vitro studies on the role of the peripheral-type benzodiazepine receptor in steroidogenesis. J. Steroid Biochem. Mol. Biol. 69, 123-130.

Cunningham, C.J., Sinnott, M., Denihan, A., Rowan, M., Walsh, J.B., O’Moore, R., Coakley, D., Coen, R.F., Lawler, B.A., O’Neill, D.D., 2001. Endogenous sex hormone levels in postmenopausal women with Alzheimer's disease. J. Clin. Endocrinol. Metab. 86, 1099-1103.

Darnaudéry, M., Koehl, M., Pallarés, M., Le Moal, M., Mayo, W., 1998. The neurosteroid pregnenolone sulfate increases cortical acetylcholine release: a microdialysis study in freely moving rats. J. Neurochem. 71, 2018-2022.

Davis, S., 1999. Androgen replacement in women: a commentary. J. Clin. Endocrinol. Metab. 84, 1886-1891.

De Vries, G.J., Wang, Z., Bullock, N.A., Numan, S., 1994. Sex differences in the effects of testosterone and its metabolites on vasopressin messenger RNA levels in the bed nucleus of the stria terminalis of rats. J. Neurosci. 14 (Part 2), 1789-1794.

Dhandapani, K.M., Brann, D.W., 2002. Protective effects of estrogen and selective estrogen receptor modulators in the brain. Biol. Reprod. 67, $1379-1385$.

Dubal, D.B., Wise, P.M., 2001. Neuroprotective effects of estradiol in middle-aged female rats. Endocrinology 142, 43-48.

Ferrario, E., Massaia, M., Aimo, G., di Ceva, P.A., Fabris, F., 1999. Dehydroepiandrosterone sulfate serum levels: no significance in diagnosing Alzheimer's disease. J. Endocrinol. Invest. 22, 81.

Ferreira, A., Caceres, A., 1991. Estrogen-enhanced neurite growth: evidence for a selective induction of tau and stable microtubules. J. Neurosci. 11, 392-400. 
Fillenbaum, G.G., Hanlon, J.T., Landerman, L.R., Schmader, K.E., 2001. Impact of estrogen use on decline in cognitive function in a representative sample of older community-resident women. Am. J. Epidemiol. 153, 137-144.

Flood, J.F., Roberts, E., 1988. Dehydroepiandrosterone sulfate improves memory in aging mice. Brain Res. 448, 178-181.

Flood, J.F., Morley, J.E., Roberts, E., 1992. Memory-enhancing effects in male mice of pregnenolone and steroids metabolically derived from it. Proc. Natl. Acad. Sci. U.S.A. 89, 1567-1571.

Flood, J.F., Morley, J.E., Roberts, E., 1995. Pregnenolone sulfate enhances post-training memory processes when injected in very low doses into limbic system structures: the amygdala is by far the most sensitive. Proc. Natl. Acad. Sci. U.S.A. 92, 10806-10810.

Garcia-Segura, L.M., Wozniak, A., Azcoitia, I., Rodriguez, J.R., Hutchison, R.E., Hutchison, J.B., 1999. Aromatase expression by astrocytes after brain injury: implications for local estrogen formation in brain repair. Neuroscience 89, 567-578.

Garcia-Segura, L.M., Azcoitia, I., Doncarlos, L.L., 2001. Neuroprotection by estradiol. Prog. Neurobiol. 63, 29-60.

Genazzani, A.D., Petraglia, F., Bernardi, F., Casarosa, E., Salvestroni, C., Tonetti, A., Nappi, R.E., Luisi, S., Palumbo, M., Purdy, R.H., Luisi, M., 2002. Circulating levels of alloprenanolone in humans: gender, age and endocrine influences. J. Clin. Endocrinol. Metab. 83, 2099-2103.

Ghoumari, A.M., Ibanez, C., el-Etr, M., Leclerc, P., Eychenne, B., Baulieu, E.E., Schumacher, M., 2003. Progesterone and its metabolites increase myelin basic protein expression in organotypic slice cultures of rat cerebellum. J. Neurochem. 86, 848-859.

Gomez-Isla, T., Price, J.L., McKeel, D.W., Morris, J.C., Growdon, J.H., Hyman, B.T., 1996. Profound loss of layer II entorhinal cortex neurons occurs in very mild Alzheimer's disease. J. Neurosci. 16, 4491-4500.

Gonzalez Deniselle, M.C., Lopez-Costa, J.J., Saavedra, J.P., Pietranera, L., Gonzalez, S.L., Garay, L., Guennoun, R., Schumacher, M., Denicola, A.F., 2002. Progesterone neuroprotection in the wobbler mouse, a genetic model of spinal cord motor disease. Neurobiol. Dis. 11, 457468.

Goodman, Y., Bruce, A.J., Cheng, B., Mattson, M.P., 1996. Estrogens attenuate and corticosterone exacerbates excitotoxicity, oxidative injury, and amyloid beta-peptide toxicity in hippocampal neurons. J. Neurochem. 66, 1836-1844.

Gould, E., Tanapat, P., Rydel, T., Hastings, N., 2000. Regulation of hippocampal neurogenesis in adulthood. Biol. Psychiatry 48, 715-720.

Gouras, G.K., Xu, H., Gross, R.S., Greenfield, J.P., Hai, B., Wang, R., Greengard, P., 2000. Testosterone reduces neuronal secretion of Alzheimer's beta-amyloid peptides. Proc. Natl. Acad. Sci. U.S.A. 97, 1202-1205.

Green, P.S., Perez, E.J., Calloway, T., Simpkins, J.W., 2000. Estradiol attenuation of beta-amyloid-induced toxicity: a comparison of MTT and calcein AM assays. J. Neurocytol. 29, 419-423.

Gursoy, E., Cardounel, A., Kalimi, M., 2001. Pregnenolone protects mouse hippocampal (HT-22) cells against glutamate and amyloid beta protein toxicity. Neurochem. Res. 26, 15-21.

Gutai, J.P., Meyer, W.J., Kowarski, A.A., Migeon, C.J., 1977. Twenty-fourhour integrated concentrations of progesterone, 17-hydroxyprogesterone and cortisol in normal male subjects. J. Clin. Endocrinol. Metab. 44, 116-120.

Guth, L., Zhang, Z., Roberts, E., 1994. Key role for pregnenolone in combination therapy promotes recovery after spinal cord injury. Proc. Natl. Acad. Sci. U.S.A. 91, 12308-12312.

Hammond, G.L., Hirvonen, J., Vihko, R., 1983. Progesterone, androstenedione, testosterone, 5alpha-dihydrotestosterone and androsterone concentrations in specific regions of the human brain. J. Steroid Biochem. $18,185-189$.

Hammond, J., Le, Q., Goodyer, C., Gelfand, M., Trifiro, M., LeBlanc, A., 2001. Testosterone-mediated neuroprotection through the androgen receptor in human primary neurons. J. Neurochem. 77, 1319-1326.

Hampl, R., Morfin, R., Starka, L., 1997. Minireview: 7-hydroxylated derivatives of dehydroepiandrosterone. What are they good for? Endocr. Regul. 31, 211-218.
Hauw, J.J., Duyckaerts, C., 2002. Dementia, the fate of the brain? Neuropathological point of view. C. R. Biol. 325, 655-664.

Hebert, L.E., Beckett, L.A., Scherr, P.A., Evans, D.A., 2001. Annual incidence of Alzheimer disease in the United States projected to the years 2000 through 2050. Alzheimer Dis. Assoc. Disord. 15, 169-173.

Henderson, V.W., Paganini-Hill, A., Emanuel, C.K., Dunn, M.E., Buckwalter, J.G., 1994. Estrogen replacement therapy in older women. Comparisons between Alzheimer's disease cases and nondemented control subjects. Arch. Neurol. 51, 896-900.

Henderson, V.W., Paganini-Hill, A., Miller, B.L., Elbe, R.J., Reyes, P.F., Shoupe, D., McCleary, C.A., Klein, R.A., Hake, A.M., Farlow, M.R., 2000. Estrogen for Alzheimer's disease in women: randomized, double-blind, placebo-controlled trial. Neurology 54, 295-301.

Henzl, M.R., Edwards, J.A., 2000. Pharmacology of progestins: 17alpha-hydroxyprogesterone derivatives and progestins of the first and second generation. In: Sitruk-Ware, R., Mishell, D.R. (Eds.), Progestins and Antiprogestins in Clinical Practice. Marcel Dekker, New York, pp. 101-132.

Herbert, J., 1995. The age of dehydroepiandrosterone. Lancet 345, 1193 1194.

Hill, M., Lukac, D., Lapcik, O., Sulcova, J., Hampl, R., Pouzar, V., Starka, L., 1999. Age relationships and sex differences in serum levels of pregnenolone and 17-hydroxypregnenolone in healthy subjects. Clin. Chem. Lab. Med. 37, 439-447.

Hutchison, J.B., Steimer, T., 1981. Brain 5 $\beta$-reductase: a correlate of behavioral sensitivity to androgen. Science 213, 244-246.

Ibanez, C., Shields, S.A., Liere, P., el-Etr, M., Baulieu, E.E., Schumacher, M., Franklin, R.J.M. Systemic progesterone administration results in a partial reversal of the age-associated decline in CNS remyelination following toxin-induced demyelination in male rats. Neuropathol. Appl. Neurobiol., in press.

Inoue, T., Akahira, J., Suzuki, T., Darnel, A.D., Kaneko, C., Takahashi, K., Hatori, M., Shirane, R., Kumabe, T., Kurokawa, Y., Satomi, S., Sasano, H., 2002. Progesterone production and actions in the human central nervous system and neurogenic tumors. J. Clin. Endocrinol. Metab. 87, 5325-5331.

Isaacson, R.L., Varner, J.A., Baars, J.M., De Wied, D., 1995. The effects of pregnenolone sulfate and ethylestrenol on retention of a passive avoidance task. Brain Res. 689, 79-84.

Ishida, Y., Ishida, Y., Heersche, J.N., 2002. Pharmacologic doses of medroxyprogesterone may cause bone loss through glucocorticoid activity: an hypothesis. Osteoporos. Int. 13, 601-605.

Jacobs, D.M., Tang, X.M., Stern, Y., Sano, M., Marder, K., Bell, K.L., Schofield, P., Dooneief, G., Gurland, B., Mayeux, R., 1998. Cognitive function in nondemented older women who took estrogen after menopause. Neurology 50, 368-373.

Janowsky, J.S., Oviatt, S.K., Orwoll, E.S., 1994. Testosterone influences spatial cognition in older men. Behav. Neurosci. 108, 325-332.

Jenkins, J.S., Hall, C.J., 1977. Metabolism of $\left[{ }^{14} \mathrm{C}\right]$ testosterone by human foetal and adult brain tissue. J. Endocrinol. 74, 425-429.

Jiang, N., Chopp, M., Stein, D.G., Feldblum, S., 1996. Progesterone is neuroprotective after transient middle cerebral artery occlusion in male rats. Brain Res. 735, 101-107.

Johnson, A.E., Coirini, H., McEwen, B.S., Insel, T.R., 1989. Testosterone modulates oxytocin binding in the hypothalamus of castrated male rats. Neuroendocrinology 50, 199-203.

Johnson, D.A., Rhodes, M.E., Boni, R.L., Li, P.K., 1997. Chronic steroid sulfatase inhibition by $(p-O$-sulfamoyl $)-N$-tetradecanoyl tyramine increases dehydroepiandrosterone sulfate in whole brain. Life Sci. $61, \mathrm{~L}$.

Jones, K.J., Brown, T.J., Damaser, M., 2001. Neuroprotective effects of gonadal steroids on regenerating peripheral motoneurons. Brain Res. Rev. 37, 372-382.

Kalimi, M., Regelson, W., 1990. The Biological Role of Dehydroepiandrosterone. Walter de Gruyter, Berlin.

Kalmijn, S., Launer, L.J., Stolk, R.P., De Jong, F.H., Pols, H.A., Hofman, A., Breteler, M.M., Lamberts, S.W., 1998. A prospective study on 
cortisol, dehydroepiandrosterone sulfate, and cognitive function in the elderly. J. Clin. Endocrinol. Metab. 83, 3487-3492.

Karishma, K.K., Herbert, J., 2002. Dehydroepiandrosterone (DHEA) stimulates neurogenesis in the hippocampus of the rat, promotes survival of newly formed neurons and prevents corticosterone-induced suppression. Eur. J. Neurosci. 16, 445-453.

Kawano, H., Motoyama, T., Hirai, N., Yoshimura, T., Kugiyama, K., Ogawa, H., Okamura, H., Yasue, H., 2001. Effect of medroxyprogesterone acetate plus estradiol on endothelium-dependent vasodilation in postmenopausal women. Am. J. Cardiol. 87, 238-240.

Kawas, C., Resnick, S., Morrison, A., Brookmeyer, R., Corrada, M., Zonderman, A., Bacal, C., Lingle, D.D., Metter, E., 1997. A prospective study of estrogen replacement therapy and the risk of developing Alzheimer's disease: the Baltimore Longitudinal Study of Aging. Neurology 48, 1517-1521 (published erratum appeared in 1998 in Neurology 51 (2), 654).

Khaw, K.T., 1992. Epidemiology of the menopause. Br. Med. Bull. 48, 249-261.

Kimonides, V.G., Spilantini, M.G., Sofroniew, M.V., Fawcett, J.W., Herbert, J., 1999. Dehydroepiandrosterone antagonizes the neurotoxic effects of corticosterone and translocation of stress-activated protein kinase 3 in hippocampal primary cultures. Neuroscience 89, 429-436.

Knapstein, P., David, A., Wu, C.H., Archer, D.F., Flickinger, G.L., Tochstone, J.C., 1968. Metabolism of free and sulfoconjugated DHEA in brain tissue in vivo and in vitro. Steroids 11, 885-896.

Koenig, H., Schumacher, M., Ferzaz, B., Do Thi, A.N., Ressouches, A., Guennoun, R., Jung-Testas, I., Robel, P., Akwa, Y., Baulieu, E.E., 1995. Progesterone synthesis and myelin formation by Schwann cells. Science 268, 1500-1503.

Korneyev, A., Pan, B.S., Polo, A., Romeo, E., Guidotti, A., Costa, E., 1993. Stimulation of brain pregnenolone synthesis by mitochondrial diazepam binding inhibitor receptor ligands in vivo. J. Neurochem. 61, $1515-1524$.

Krishnan, V., Heath, H., Bryant, H.U., 2000. Mechanism of action of estrogens and selective estrogen receptor modulators. Vitam. Horm. 60, 123-147.

Labrie, F., Belanger, A., Cusan, L., Gomez, J.L., Candas, B., 1997a. Marked decline in serum concentrations of adrenal C19 sex steroid precursors and conjugated androgen metabolites during aging. J. Clin. Endocrinol. Metab. 82, 2396-2402.

Labrie, F., Bélanger, A., Cusan, L., Candas, B., 1997b. Physiological changes in dehydroepiandrosterone are not reflected by serum levels of active androgens and estrogens but of their metabolites: intracrinology. J. Clin. Endocrinol. Metab. 82, 2403-2409.

Lachance, Y., Luu-The, V., Labrie, C., Simard, J., Dumont, M., de Launoit, Y., Guerin, S., LeBlanc, G., Labrie, F., 1990. Characterization of human 3beta-hydroxysteroid dehydrogenase/delta5-delta4-isomerase gene and its expression in mammalian cells. J. Biol. Chem. 265, 20469-20475 (published erratum appeared in 1992 in J. Biol. Chem. 267 (5), 3551).

Lachance, Y., Luu-The, V., Verreault, H., Dumont, M., Rheaume, E., LeBlanc, G., Labrie, F., 1991. Structure of the human type II 3beta-hydroxysteroid dehydrogenase/delta5-delta4 isomerase (3beta-HSD) gene: adrenal and gonadal specificity. DNA Cell Biol. 10, 701-711.

Lacroix, C., Fiet, J., Benais, J.P., Gueux, B., Bonete, R., Villette, J.M., Gourmel, B., Dreux, C., 1987. Simultaneous radioimmunoassay of progesterone, androst-4-enedione, pregnenolone, dehydroepiandrosterone and 17-hydroxyprogesterone in specific regions of human brain. J. Steroid Biochem. 28, 317-325.

Ladurelle, N., Eychenne, B., Denton, D., Blair-West, J., Schumacher, M., Robel, P., Baulieu, E.E., 2000. Prolonged intracerebroventricular infusion of neurosteroids affects cognitive performances in the mouse. Brain Res. 858, 371-379.

Lamberts, S.W., van den Beld, A.W., van der Lely, A.J., 1997. The endocrinology of aging (see comments). Science 278, 419-424.

Lanthier, A., Patwardhan, V.V., 1986. Sex steroids and 5-en-3betahydroxysteroids in specific regions of the human brain and cranial nerves. J. Steroid Biochem. 25, 445-449.
Lathe, R., 2002. Steroid and sterol 7-hydroxylation: ancient pathways. Steroids 67, 967-977.

Laughlin, G.A., Barrett-Connor, E., 2000. Sexual dimorphism in the influence of advanced aging on adrenal hormone levels: the Rancho Bernardo Study. J. Clin. Endocrinol. Metab. 85, 3561-3568.

Leblhuber, F., Neubauer, C., Peichl, M., Reisecker, F., Steinparz, F.X., Windhager, E., Dienstl, E., 1993. Age and sex differences of dehydroepiandrosterone sulfate (DHEAS) and cortisol (CRT) plasma levels in normal controls and Alzheimer's disease (AD). Psychopharmacology 111, 23-26.

Le Fur, G., Guillot, F., Alexander, J., Muller, J.C., 2002. Research strategies in the pharmaceutical industry to cope with problems of ageing. C. R. Biol. 325, 643-654.

Le Goascogne, C., Gouézou, M., Robel, P., Defaye, G., Chambaz, E., Waterman, M.R., Baulieu, E.E., 1989. The cholesterol side-chain cleavage complex in human brain white matter. J. Neuroendocrinol. 1, $153-156$.

Legrain, S., Berr, C., Frenoy, N., Gourlet, V., Debuire, B., Baulieu, E.E., 1995. Dehydroepiandrosterone sulfate in a long-term care aged population. Gerontology 41, 343-351.

Li, P.K., Rhodes, M.E., Jagannathan, S., Johnson, D.A., 1995. Reversal of scopolamine induced amnesia in rats by the steroid sulfatase inhibitor estrone-3-O-sulfamate. Brain Res. Cogn. Brain Res. 2, 251-254.

Li, P.K., Rhodes, M.E., Burke, A.M., Johnson, D.A., 1997. Memory enhancement mediated by the steroid sulfatase inhibitor ( $p$ - $O$-sulfamoyl)- $N$-tetradecanoyl tyramine. Life Sci. 60, L45-L51.

Liere, P., Akwa, Y., Weill, E., Eychenne, B., Pianos, A., Robel, P., Sjovall, J., Schumacher, M., Baulieu, E.E., 2000. Validation of an analytical procedure to measure trace amounts of neurosteroids in brain tissue by gas chromatography-mass spectrometry. J. Chromatogr. B: Biomed. Sci. Appl. 739, 301-312.

Littleton, K., Ostrowski, N.L., Cox, D.A., Rossberg, M.I., Hurn, P.D., 2002. Selective estrogen receptor modulators: tissue actions and potential for CNS protection. CNS Drug Rev. 8, 309-330.

Lorenzo, A., Diaz, H., Carrer, H., Caceres, A., 1992. Amygdala neurons in vitro-neurite growth and effects of estradiol. J. Neurosci. Res. 33, $418-435$.

Loria, R.M., 2002. Immune up-regulation and tumor apoptosis by androstene steroids. Steroids 67, 953-966.

Lupien, S.J., De Leon, M., de Santi, S., Convit, A., Tarshish, C., Nair, N.P., Thakur, M., McEwen, B.S., Hauger, R.L., Meaney, M.J., 1998. Cortisol levels during human aging predict hippocampal atrophy and memory deficits (see comments). Nat. Neurosci. 1, 69-73 (published erratum appeared in 1998 in Nat. Neurosci. 1 (4), 329).

Lupien, S.J., Nair, N.P., Briere, S., Maheu, F., Tu, M.T., Lemay, M., McEwen, B.S., Meaney, M.J., 1999. Increased cortisol levels and impaired cognition in human aging: implication for depression and dementia in later life. Rev. Neurosci. 10, 117-139.

Maggi, R., Poletti, A., Casulari, L.A., Pimpinelli, F., Piva, F., Zanisi, M.R., Martini, L., 1998. Effects and metabolism of steroid hormones in human neuroblastoma cells. Steroids 63, 257-262.

Magnaghi, V., Cavarretta, I., Zucchi, I., Susani, L., Rupprecht, R., Hermann, B., Martini, L., Melcangi, R.C., 1999. Po gene expression is modulated by androgens in the sciatic nerve of adult male rats. Mol. Brain Res. 70, 36-44.

Magnaghi, V., Cavarretta, I., Galbiati, M., Martini, L., Melcangi, R.C., 2001. Neuroactive steroids and peripheral myelin proteins. Brain Res. Brain Res. Rev. 37, 360-371.

Malsbury, C.W., McKay, K., 1994. Neurotrophic effects of testosterone on the medial nucleus of the amygdala in adult male rats. J. Neuroendocrinol. 6, 57-69.

Manly, J.J., Merchant, C.A., Jacobs, D.M., Small, S.A., Bell, K., Ferin, M., Mayeux, R., 2000. Endogenous estrogen levels and Alzheimer's disease among postmenopausal women. Neurology 54, 833-837.

Mathis, C., Paul, S.M., Crawley, J.N., 1994. The neurosteroid pregnenolone sulfate blocks NMDA antagonist-induced deficits in a passive avoidance memory task. Psychopharmacology 116, 201-206. 
Mathis, C., Vogel, E., Cagniard, B., Criscuolo, F., Ungerer, A., 1996. The neurosteroid pregnenolone sulfate blocks deficits induced by a competitive NMDA antagonist in active avoidance and lever-press learning tasks in mice. Neuropharmacology 35, 1057-1064.

Mathur, R.S., Landgrebe, S.C., Moody, L.O., Semmens, J.P., Williamson, H.O., 1985. The effect of estrogen treatment on plasma concentrations of steroid hormones, gonadotropins, prolactin and sex hormone-binding globulin in post-menopausal women. Maturitas 7, 129-133.

Mathur, C., Prasad, V.V.K., Raju, V.S., Welch, M., Lieberman, S., 1993. Steroids and their conjugates in the mammalian brain. Proc. Natl. Acad. Sci. U.S.A. 90, 85-88.

Matsunaga, M., Ukena, K., Tsutsui, K., 2001. Expression and localization of cytochrome P450 17alpha-hydroxylase/c17,20-lyase in the avian brain. Brain Res. 899, 112-122.

Maurice, T., Junien, J.L., Privat, A., 1997. Dehydroepiandrosterone sulfate attenuates dizocilpine-induced learning impairment in mice via sigma 1-receptors. Behav. Brain Res. 83, 159-164.

Maurice, T., Su, T.P., Privat, A., 1998. Sigma1 $(\sigma 1)$ receptor agonists and neurosteroids attenuate B25-35-amyloid peptide-induced amnesia in mice through a common mechanism. Neuroscience 83, 413-428.

Mayo, W., Dellu, F., Robel, P., Cherkaoui, J., Le Moal, M., Baulieu, E.E., Simon, H., 1993. Infusion of neurosteroids into the nucleus basalis magnocellularis affects cognitive processes in the rat. Brain Res. 607, 324-328.

Mazat, L., Lafont, S., Debuire, B., Tessier, J.F., Dartigues, J.F., Baulieu, E.E., 2001. Prospective measurements of dehydroepiandrosterone sulfate in a cohort of elderly subjects: relationship, to gender, subjective health, smoking habits, and 10-year mortality. Proc. Natl. Acad. Sci. U.S.A. 98, 8145-8150.

McEwen, B.S., 2001. Invited review: estrogens effects on the brain: multiple sites and molecular mechanisms. J. Appl. Physiol. 91, 27852801.

McEwen, B.S., De Leon, M.J., Lupien, S.J., Meaney, M.J., 1999. Corticosteroids, the aging brain and cognition. Trends Endocrinol. Metab. 10, 92-96.

McIntosh, M.K., Pan, J.S., Berdanier, C.D., 1993. In vitro studies on the effects of dehydroepiandrosterone and corticosterone on hepatic-steroid receptor-binding and mitochondrial respiration. Comp. Biochem. Physiol. 104, 147-153.

McNeill, A.M., Zhang, C., Stanczyk, F.Z., Duckles, S.P., Krause, D.N., 2002. Estrogen increases endothelial nitric oxide synthase via estrogen receptors in rat cerebral blood vessels: effect preserved after concurrent treatment with medroxyprogesterone acetate or progesterone. Stroke 33, 1685-1691.

Melcangi, R.C., Magnaghi, V., Cavarretta, I., Martini, L., Piva, F., 1998a. Age-induced decrease of glycoprotein Po and myelin basic protein gene expression in the rat sciatic nerve. Repair by steroid derivatives. Neuroscience 85, 569-578.

Melcangi, R.C., Magnaghi, V., Cavarretta, I., Riva, M.A., Piva, F., Martini, L., 1998b. Effects of steroid hormones on gene expression of glial markers in the central and peripheral nervous system: variations induced by aging. Exp. Gerontol. 33, 827-836.

Melcangi, R.C., Magnaghi, V., Cavarretta, I., Zucchi, I., Bovolin, P., D’Urso, D., Martini, L., 1999. Progesterone derivatives are able to influence peripheral myelin protein 22 and P0 gene expression: possible mechanisms of action. J. Neurosci. Res. 56, 349-357.

Mellon, S.H., Miller, W.L., 1989. Extraadrenal steroid 21-hydroxylation is not mediated by P450c21. J. Clin. Invest. 84, 1497-1502.

Mellon, S.H., Vaudry, H., 2001. Biosynthesis of neurosteroids and regulation of their synthesis. Int. Rev. Neurobiol. 46, 33-78.

Mellon, S.H., Griffin, L.D., Compagnone, N.A., 2001. Biosynthesis and action of neurosteroids. Brain Res. Brain Res. Rev. 37, 3-12.

Mensah-Nyagan, A.G., Do-Rego, J.L., Beaujean, D., Luu-The, V., Pelletier, G., Vaudry, H., 1999. Neurosteroids: expression of steroidogenic enzymes and regulation of steroid biosynthesis in the central nervous system. Pharmacol. Rev. 51, 63-81.
Meziane, H., Mathis, C., Paul, S.M., Ungerer, A., 1996. The neurosteroid pregnenolone sulfate reduces learning deficits induced by scopolamine and has promnestic effects in mice performing an appetitive learning task. Psychopharmacology (Berl) 126, 323-330.

Miyagawa, K., Rosch, J., Stanczyk, F., Hermsmeyer, K., 1997. Medroxyprogesterone interferes with ovarian steroid protection against coronary vaso spasm. Nat. Med. 3, 324-327.

Morales, A.J., Nolan, J.J., Nelson, J.C., Yen, S.S.C., 1994. Effects of replacement dose of dehydroepiandrosterone in men and women of advancing age. J. Clin. Endocrinol. Metab. 78, 1360-1367.

Morales, A.J., Haubrich, R.H., Hwang, J.Y., Asakura, H., Yen, S.S., 1998. The effect of six months treatment with $100 \mathrm{mg}$ daily dose of dehydroepiandrosterone (DHEA) on circulating sex steroids, body composition and muscle strength in age-advanced men and women. Clin. Endocrinol. 49, 421-432.

Morfin, R., Young, J., Corpechot, C., Egestad, B., Sjovall, J., Baulieu, E.E., 1992. Neurosteroids: pregnenolone in human sciatic nerves. Proc. Natl. Acad. Sci. U.S.A. 89, 6790-6793.

Morfin, R., Lafaye, P., Cotillon, A.C., Nato, F., Chmielewski, V., Pompon, D., 2000. 7Alpha-hydroxy-dehydroepiandrosterone and immune response. Ann. N. Y. Acad. Sci. 917, 971-982.

Morley, J.E., Kaiser, F., Raum, W.J., Perry, H.M., Flood, J.F., Jensen, J., Silver, A.J., Roberts, E., 1997a. Potentially predictive and manipulable blood serum correlates of aging in the healthy human male: progressive decreases in bioavailable testosterone, dehydroepiandrosterone sulfate, and the ratio of insulin-like growth factor 1 to growth hormone. Proc. Natl. Acad. Sci. U.S.A. 94, 7537-7542.

Morley, J.E., Kaiser, F.E., Perry, H.M., Patrick, P., Morley, P.M., Stauber, P.M., Vellas, B., Baumgartner, R.N., Garry, P.J., 1997b. Longitudinal changes in testosterone, luteinizing hormone, and follicle-stimulating hormone in healthy older men. Metabolism 46, 410-413.

Mulnard, R.A., Cotman, C.W., Kawas, C., van Dyck, C.H., Sano, M., Doody, R., Koss, E., Pfeiffer, E., Jin, S., Gamst, A., Grundman, M., Thomas, R., Thal, L.J., 2000. Estrogen replacement therapy for treatment of mild to moderate Alzheimer disease: a randomized controlled trial. J. Am. Med. Assoc. 283, 1007-1015.

Murakami, K., Fellous, A., Baulieu, E.E., Robel, P., 2000. Pregnenolone binds to microtubule-associated protein 2 and stimulates microtubule assembly. Proc. Natl. Acad. Sci. U.S.A. 97, 3579-3584.

Murialdo, G., Nobili, F., Rollero, A., Gianelli, M.V., Copello, F., Rodriguez, G., Polleri, A., 2000. Hippocampal perfusion and pituitaryadrenal axis in Alzheimer's disease. Neuropsychobiology 42, 51-57.

Mushayandebvu, T., Castracane, V.D., Gimpel, T., Adel, T., Santoro, N., 1996. Evidence for diminished midcycle ovarian androgen production in older reproductive aged women. Fertil. Steril. 65, 721-723.

Nafziger, A.N., Bowlin, S.J., Jenkins, P.L., Pearson, T.A., Melcangi, R.C., Celotti, F., Ballabio, M., Poletti, A., Castano, P., Martini, L., Biegon, A., Fischette, C.T., Rainbow, T.C., McEwen, B.S., 1998. Longitudinal changes in dehydroepiandrosterone concentrations in men and women. J. Lab. Clin. Med. 131, 316-323.

Nichols, N.R., Zieba, M., Bye, N., 2001. Do glucocorticoids contribute to brain aging? Brain Res. Brain Res. Rev. 37, 273-286.

Nilsen, J., Brinton, R.D., 2002. Impact of progestins on estrogen-induced neuroprotection: synergy by progesterone and 19-norprogesterone and antagonism by medroxyprogesterone acetate. Endocrinology 143, 205212.

Orentreich, N., Brind, J.L., Rizer, R.L., Vogelman, J.H., 1984. Age changes and sex differences in serum dehydroepiandrosterone sulfate concentrations throughout adulthood. J. Clin. Endocrinol. Metab. 59, 551-555.

Ott, A., Breteler, M.M., van Harskamp, F., Stijnen, T., Hofman, A., 1998. Incidence and risk of dementia: the Rotterdam Study. Am. J. Epidemiol. 147, 574-580.

Padgett, D.A., Loria, R.M., 1994. In vitro potentiation of lymphocyte activation by dehydroepiandrosterone, androstenediol and androstenetriol. J. Immunol. 153, 1544-1552.

Paganini-Hill, A., Henderson, V.W., 1994. Estrogen deficiency and risk of Alzheimer's disease in women. Am. J. Epidemiol. 140, 256-261. 
Paganini-Hill, A., Henderson, V.W., 1996. Estrogen replacement therapy and risk of Alzheimer disease. Arch. Intern. Med. 156, 2213-2217.

Pallarés, M., Darnaudéry, M., Day, J., Le Moal, M., Mayo, W., 1998. The neurosteroid pregnenolone sulfate infused into the nucleus basalis increases both acetylcholine release in the frontal cortex or amygdala and spatial memory. Neuroscience $87,551-558$.

Papadopoulos, V., Guarneri, P., Kreuger, K.E., Guidotti, A., Costa, E., 1992. Pregnenolone biosynthesis in C6-2B glioma cell mitochondria: regulation by a mitochondrial diazepam binding inhibitor receptor. Proc. Natl. Acad. Sci. U.S.A. 89, 5113-5117.

Paul, S.M., Purdy, R.H., 1992. Neuroactive steroids. FASEB J. 6, 23112322.

Peters, A., 1996. Age-related changes in oligodendrocytes in monkey cerebral cortex. J. Comp. Neurol. 371, 153-163.

Peters, A., 2002. Structural changes in the normally aging cerebral cortex of primates. Prog. Brain Res. 136, 455-465.

Peters, A., Morrison, J.H., Rosene, D.L., Hyman, B.T., 1998. Feature article: are neurons lost from the primate cerebral cortex during normal aging? Cereb. Cortex 8, 295-300.

Petersen, R.C., Doody, R., Kurz, A., Mohs, R.C., Morris, J.C., Rabins, P.V., Ritchie, K., Rossor, M., Thal, L., Winblad, B., 2001. Current concepts in mild cognitive impairment. Arch. Neurol. 58, 1985-1992.

Phan, V.L., Su, T.P., Privat, A., Maurice, T., 1999. Modulation of steroidal levels by adrenalectomy/castration and inhibition of neurosteroid synthesis enzymes affect sigma1 receptor-mediated behaviour in mice. Eur. J. Neurosci. 11, 2385-2396.

Phillips, S.M., Sherwin, B.B., 1992. Effects of estrogen on memory function in surgically menopausal women. Psychoneuroendocrinology 17, 485-495.

Prasad, V.V., el-Etr, M., Ponticorvo, L., Lieberman, S., 1985. Detection in extracts of bovine brain of lipophilic complexes of sulfate esters of cholesterol and beta-sitosterol. Proc. Natl. Acad. Sci. U.S.A. 82, 2657-2659.

Rako, S., 1998. Testosterone deficiency: a key factor in the increased cardiovascular risk to women following hysterectomy or with natural aging? J. Women's Health 7, 825-829.

Ravaglia, G., Forti, P., Maioli, F., Boschi, F., Bernardi, M., Pratelli, L., Pizzoferrato, A., Gasbarrini, G., 1996. The relationship of dehydroepiandrosterone sulfate (DHEAS) to endocrine-metabolic parameters and functional status in the oldest-old. Results from an Italian study on healthy free-living over-ninety-year-olds. J. Clin. Endocrinol. Metab. 81, 1173-1178.

Reddy, D.S., Kulkarni, S.K., 1998. The effects of neurosteroids on acquisition and retention of a modified passive-avoidance learning task in mice. Brain Res. 791, 108-116.

Resnick, S.M., Maki, P.M., Golski, S., Kraut, M.A., Zonderman, A.B., 1998. Effects of estrogen replacement therapy on PET cerebral blood flow and neuropsychological performance. Horm. Behav. 34, 171-182.

Rhodes, M.E., Li, P.K., Burke, A.M., Johnson, D.A., 1997. Enhanced plasma DHEAS, brain acetylcholine and memory mediated by steroid sulfatase inhibition. Brain Res. 773, 28-32.

Rice, M.M., Graves, A.B., McCurry, S.M., Gibbons, L.E., Bowen, J.D., McCormick, W.C., Larson, E.B., 2000. Postmenopausal estrogen and estrogen-progestin use and 2-year rate of cognitive change in a cohort of older Japanese American women: the Kame Project. Arch. Intern. Med. 160, 1641-1649.

Robel, P., Schumacher, M., Baulieu, E.E., 1999. Neurosteroids: from definition and biochemistry to physiological function. In: Baulieu, E.E., Robel, P., Schumacher, M. (Eds.), Neurosteroids. A New Regulatory Function in the Nervous System. Humana Press, Totowa, NJ, pp. 1-25.

Robert, F., Guennoun, R., Desarnaud, F., Do-Thi, A., Benmessahel, Y., Baulieu, E.E., Schumacher, M., 2001. Synthesis of progesterone in Schwann cells: regulation by sensory neurons. Eur. J. Neurosci. 13, 916-924.

Roe, E.B., Chiu, K.M., Arnaud, C.D., 2000. Selective estrogen receptor modulators and postmenopausal health. Adv. Intern. Med. 45, 259-278.
Romeo, E., Cavallaro, S., Korneyev, A., Kozikowski, A.P., Ma, D., Polo, A., Costa, E., Guidotti, A., 1993. Stimulation of brain steroidogenesis by 2 -aryl-indole-3-acetamide derivatives acting at the mitochondrial diazepam-binding inhibitor receptor complex. J. Pharmacol. Exp. Ther. 267, 462-471.

Rosano, G.M., Webb, C.M., Chierchia, S., Morgani, G.L., Gabraele, M., Sarrel, P.M., de Ziegler, , Collins, P., 2000. Natural progesterone, but not medroxyprogesterone acetate, enhances the beneficial effect of estrogen on exercise-induced myocardial ischemia in postmenopausal women. J. Am. Coll. Cardiol. 36, 2154-2159.

Rowe, J.W., Kahn, R.L., 1997. Successful aging. Gerontology 37, 433440.

Saaresranta, T., Irjala, K., Polo, K., Polo, O., 2002. Medroxyprogesterone-induced endocrine alterations after menopause. Menopause 9, 288-292.

Saitoh, H., Hirato, K., Yanaihara, T., Nakayama, T., 1982. A study of 5alpha-reductase in human fetal brain. Endocrinol. Jpn. 29, 461-467.

Schonknecht, P., Pantel, J., Klinga, K., Jensen, M., Hartmann, T., von Bergmann, K., Beyreuther, K., Schroder, J., 2001. Reduced cerebrospinal fluid estradiol levels are associated with increased beta-amyloid levels in female patients with Alzheimer's disease. Neurosci. Lett. 307, 83-85.

Schumacher, M., Robert, F., 2002. Progesterone: synthesis, metabolism, mechanisms of action, and effects in the nervous system. In: Pfaff, D.W., Arnold, A.P., Etgen, A.M., Fahrbach, S.E., Rubin, R.T. (Eds.), Hormones, Brain and Behavior, vol. 3. Academic Press, Amsterdam, pp. 683-745.

Schumacher, M., Hutchison, R.E., Hutchison, J.B., 1991. Inhibition of hypothalamic aromatase activity by $5 \beta$-dihydrotestosterone. J. Neuroendocrinol. 3, 221-226.

Schumacher, M., Akwa, Y., Guennoun, R., Robert, F., Labombarda, F., Desarnaud, F., Robel, P., De, N., Baulieu, E.E., 2000. Steroid synthesis and metabolism in the nervous system: trophic and protective effects. J. Neurocytol. 29, 307-326.

Schumacher, M., Guennoun, R., Mercier, G., Desarnaud, F., Lacor, P., Benavides, J., Ferzaz, B., Robert, F., Baulieu, E.E., 2001. Progesterone synthesis and myelin formation in peripheral nerves. Brain Res. Rev. 37, 343-359.

Serra, M., Madau, P., Chessa, M.F., Caddeo, M., Sanna, E., Trapani, G., Franco, M., Liso, G., Purdy, R.H., Barbaccia, M.L., Biggio, G., 1999. 2-Phenyl-imidazo[1,2-a]pyridine derivatives as ligands for peripheral benzodiazepine receptors: stimulation of neurosteroid synthesis and anticonflict action in rats. Br. J. Pharmacol. 127, 177-187.

Sih, R., Morley, J.E., Kaiser, F.E., Perry, H.M., Patrick, P., Ross, C., 1997. Testosterone replacement in older hypogonadal men: a 12-month randomized controlled trial. J. Clin. Endocrinol. Metab. 82, 1661-1667.

Simard, J., Rheaume, E., Mebarki, F., Sanchez, R., New, M.I., Morel, Y., Labrie, F., 1995. Molecular basis of human 3beta-hydroxysteroid dehydrogenase deficiency. J. Steroid Biochem. Mol. Biol. 53, 127-138.

Sitruk-Ware, R., 2000. Progestins in hormonal replacement therapy and prevention of endometrial disease. In: Sitruk-Ware, R., Mishell, D.R. (Eds.), Progestins and Antiprogestins in Clinical Practice. Marcel Dekker, New York, pp. 269-277.

Sitruk-Ware, R., 2002. Progestogens in hormonal replacement therapy: new molecules, risks, and benefits. Menopause 9, 6-15.

Sloane, P.D., Zimmerman, S., Suchindran, C., Reed, P., Wang, L., Boustani, M., Sudha, S., 2002. The public health impact of Alzheimer's disease, 2000-2050: potential implication of treatment advances. Annu. Rev. Public Health 23, 213-231.

Smith, Y.R., Giordani, B., Lajiness, O., Zubieta, J.K., 2001. Long-term estrogen replacement is associated with improved nonverbal memory and attentional measures in postmenopausal women. Fertil. Steril. 76, 1101-1107.

Snowdon, D.A., Greiner, L.H., Mortimer, J.A., Riley, K.P., Greiner, P.A., Markesbery, W.R., 1997. Brain infarction and the clinical expression of Alzheimer disease: the Nun Study. J. Am. Med. Assoc. 277, 813-817. 
Snyder, P.J., Peachey, H., Hannoush, P., Berlin, J.A., Loh, L., Holmes, J.H., Dlewati, A., Staley, J., Santanna, J., Kapoor, S.C., Attie, M.F., Haddad, J.G., Strom, B.L., 1999a. Effect of testosterone treatment on bone mineral density in men over 65 years of age. J. Clin. Endocrinol. Metab. 84, 1966-1972.

Snyder, P.J., Peachey, H., Hannoush, P., Berlin, J.A., Loh, L., Lenrow, D.A., Holmes, J.H., Dlewati, A., Santanna, J., Rosen, C.J., Strom, B.L., 1999b. Effect of testosterone treatment on body composition and muscle strength in men over 65 years of age. J. Clin. Endocrinol. Metab. 84, 2647-2653.

Sowers, M.R., La Pietra, M.T., 1995. Menopause: its epidemiology and potential association with chronic diseases. Epidemiol. Res. 17, 287302 .

Steckelbroeck, S., Heidrich, D.D., Stoffel-Wagner, B., Hans, V.H., Schramm, J., Bidlingmaier, F., Klingmuller, D., 1999a. Characterization of aromatase cytochrome P450 activity in the human temporal lobe. J. Clin. Endocrinol. Metab. 84, 2795-2801.

Steckelbroeck, S., Stoffel-Wagner, B., Reichelt, R., Schramm, J., Bidlingmaier, F., Siekmann, L., Klingmuller, D., 1999b. Characterization of 17beta-hydroxysteroid dehydrogenase activity in brain tissue: testosterone formation in the human temporal lobe. J. Neuroendocrinol. 11, 457-464.

Steckelbroeck, S., Watzka, M., Reichelt, R., Hans, V.H., Stoffel-Wagner, B., Heidrich, D.D., Schramm, J., Bidlingmaier, F., Klingmuller, D., 2001a. Characterization of the 5alpha-reductase-3alpha-hydroxysteroid dehydrogenase complex in the human brain. J. Clin. Endocrinol. Metab. 86, 1324-1331.

Steckelbroeck, S., Watzka, M., Stoffel-Wagner, B., Hans, V.H., Redel, L., Clusmann, H., Elger, C.E., Bidlingmaier, F., Klingmuller, D., 2001b. Expression of the 17beta-hydroxysteroid dehydrogenase type $5 \mathrm{mRNA}$ in the human brain. Mol. Cell. Endocrinol. 171, 165-168.

Steckelbroeck, S., Watzka, M., Lutjohann, D., Makiola, P., Nassen, A., Hans, V.H., Clusmann, H., Reissinger, A., Ludwig, M., Siekmann, L., Klingmuller, D., 2002. Characterization of the dehydroepiandrosterone (DHEA) metabolism via oxysterol 7alpha-hydroxylase and 17 -ketosteroid reductase activity in the human brain. J. Neurochem. 83, 713-726.

Steimer, T., Hutchison, J.B., 1981. Metabolic control of the behavioural action of androgens in the dove brain: testosterone inactivation by 5beta-reduction. Brain Res. 209, 189-204.

Stein, D.G., 2001. Brain damage, sex hormones and recovery: a new role for progesterone and estrogen? Trends Neurosci. 24, 386-391.

Sternbach, H., 1998. Age-associated testosterone decline in men: clinical issues for psychiatry. Am. J. Psychiatry 155, 1310-1318.

Stocco, D.M., 2001. StAR protein and the regulation of steroid hormone biosynthesis. Annu. Rev. Physiol 63, 193-213.

Stoffel-Wagner, B., Watzka, M., Steckelbroeck, S., Ludwig, M., Clusmann, H., Bidlingmaier, F., Casarosa, E., Luisi, S., Elger, C.E., Beyenburg, S., 2003. Allopregnanolone serum levels and expression of 5alpha-reductase and 3alpha-hydroxysteroid dehydrogenase isoforms in hippocampal and temporal cortex of patients with epilepsy. Epilepsy Res. 54, 11-19.

Suter, U., Nave, K.A., 1999. Transgenic mouse models of CMT1A and HNPP. Ann. N. Y. Acad. Sci. 883, 247-253.

Suter, U., Snipes, G.J., 1995. Biology and genetics of hereditary motor and sensory neuropathies. Annu. Rev. Neurosci. 18, 45-75.

Tang, M.X., Jacobs, D., Stern, Y., Marder, K., Schofield, P., Gurland, B., Andrews, H., Mayeux, R., 1996. Effect of oestrogen during menopause on risk and age at onset of Alzheimer's disease. Lancet 348, 429-432.

Tanzer, L., Jones, K.J., 1997. Gonadal steroid regulation of hamster facial nerve regeneration: effects of dihydrotestosterone and estradiol. Exp. Neurol. 146, 258-264.

Tenover, J.S., 1992. Effects of testosterone supplementation in the aging male. J. Clin. Endocrinol. Metab. 75, 1092-1098.

Thomas, A.J., Nockels, R.P., Pan, H.Q., Shaffrey, C.I., Chopp, M., 1999. Progesterone is neuroprotective after acute experimental spinal cord trauma in rats. Spine 24, 2134-2138.
Trapani, G., Franco, M., Latrofa, A., Ricciardi, L., Carotti, A., Serra, M., Sanna, E., Biggio, G., Liso, G., 1999. Novel 2-phenylimidazo[1,2-a]pyridine derivatives as potent and selective ligands for peripheral benzodiazepine receptors: synthesis, binding affinity, and in vivo studies. J. Med. Chem. 42, 3934-3941.

Tsutsui, K., Ukena, K., Usui, M., Sakamoto, H., Takase, M., 2000. Novel brain function: biosynthesis and actions of neurosteroids in neurons. Neurosci. Res. 36, 261-273.

Twist, S.J., Taylor, G.A., Weddell, A., Weightman, D.R., Edwardson, J.A., Morris, J.A., 2000. Brain oestradiol and testosterone levels in Alzheimer's disease. Neurosci. Lett. 286, 1-4.

Urani, A., Privat, A., Maurice, T., 1998. The modulation by neurosteroids of the scopolamine-induced learning impairment in mice involves an interaction with sigmal $(\sigma 1)$ receptors. Brain Res. 799, 64-77.

Uzunov, D.P., Cooper, T.B., Costa, E., Guidotti, A., 1996. Fluoxetineelicited changes in brain neurosteroid content measured by negative ion mass fragmentography. Proc. Natl. Acad. Sci. U.S.A. 93, 1259912604.

Vallée, M., Mayo, W., Darnaudery, M.C.C., Young, J., Koehl, M.L.M.M., Baulieu, E.E., Robel, P., Simon, H., 1997. Neurosteroids: deficient cognitive performance in aged rats depends on low pregnenolone sulfate levels in hippocampus. Proc. Natl. Acad. Sci. U.S.A. 94, 14865-14870.

Vallée, M., Mayo, W., Le, M., 2001. Role of pregnenolone, dehydroepiandrosterone and their sulfate esters on learning and memory in cognitive aging. Brain Res. Rev. 37, 301-312.

van den Beld, A.W., Lamberts, S.W.J., 2002. Endocrine aspects of healthy ageing in men. In: Chadwick, D.J., Goode, J.A. (Eds.), Endocrine Facets of Ageing. Proceedings of the Novartis Foundation Symposium, vol. 242. Wiley, Chichester, UK, pp. 3-16.

Vermeulen, A., 1991. Clinical review 24: androgens in the aging male. J. Clin. Endocrinol. Metab. 73, 221-224.

Vermeulen, A., Verdonck, L., 1976. Radioimmunoassay of 17betahydroxy-5alpha-androstan-3-one, 4-androstene-3,17-dione, dehydroepiandrosterone, 17-hydroxyprogesterone and progesterone and its application to the human male plasma. J. Steroid Biochem. 7, 1-10.

Verwer, R.W., Dubelaar, E.J., Hermens, W.T., Swaab, D.F., 2000. Tissue cultures from adult human postmortem subcortical brain areas. J. Cell. Mol. Med. 6, 429-432.

Wakatsuki, A., Okatani, Y., Ikenoue, N., Fukaya, T., 2001. Effect of medroxyprogesterone acetate on endothelium-dependent vasodilation in postmenopausal women receiving estrogen. Circulation 104, 17731778.

Wang, M.D., Wahlström, G., Bäckström, T., 1997. The regional brain distribution of the neurosteroids pregnenolone and pregnenolone sulfate following intravenous infusion. J. Steroid Biochem. Mol. Biol. 62, 299-306.

Wang, P.N., Liao, S.Q., Liu, R.S., Liu, C.Y., Chao, H.T., Lu, S.R., Yu, H.Y., Wang, S.J., Liu, H.C., 2000. Effects of estrogen on cognition, mood, and cerebral blood flow in AD: a controlled study. Neurology 54, 2061-2066.

Watzka, M., Bidlingmaier, F., Schramm, J., Klingmuller, D., StoffelWagner, B., 1999. Sex-and age-specific differences in human brain CYP11A1 mRNA expression. J. Neuroendocrinol. 11, 901-905.

Weill-Engerer, S., David, J.P., Sazdovitch, V., Liere, P., Eychenne, B., Pianos, A., Schumacher, M., Delacourte, A., Baulieu, E.E., Akwa, Y., 2002. Neurosteroid quantification in human brain regions: comparison between Alzheimer's and non-demented patients. J. Clin. Endocrinol. Metab. 87, 5138-5143.

Weill-Engerer, S., David, J.P., Sazdovitch, V., Liere, P., Schumacher, M., Delacourte, A., Baulieu, E.E., Akwa, Y., 2003. In vitro metabolism of dehydroepiandrosterone (DHEA) to $7 \alpha$-hydroxy-DHEA and $\Delta 5$-androstene-3 $\beta, 17 \beta$-diol in specific regions of the aging brain from Alzheimer's and non-demented patients. Brain Res. 969, 117 125.

West, M.J., Kawas, C.H., Martin, L.J., Troncoso, J.C., 2000. The CA1 region of the human hippocampus is a hot spot in Alzheimer's disease. Ann. N. Y. Acad. Sci. 908, 255-259. 
Whitaker, M.D., 2001. Selective estrogen receptor modulators: from bench to bedside and back. Endocr. Pract. 7, 113-119.

White, P.C., Grossberger, D., Onufer, B.J., Chaplin, D.D., New, M.I., Dupont, B., Strominger, J.L., 1985. Two genes encoding steroid 21-hydroxylase are located near the genes encoding the fourth component of complement in man. Proc. Natl. Acad. Sci. U.S.A. 82, 1089-1093.

Wickelgren, I., 1996a. For the cortex, neuron loss may be less than thought. Science 273, 48-50.

Wickelgren, I., 1996b. Is hippocampal cell death a myth? Science 271, 1229-1230.

Winters, S.J., 1999. Current status of testosterone replacement therapy in men. Arch. Fam. Med. 8, 257-263.

Wise, P.M., Smith, M.J., Dubal, D.B., Wilson, M.E., Krajnak, K.M., Rosewell, K.L., 1999. Neuroendocrine influences and repercussions of the menopause. Endocr. Rev. 20, 243-248.

Wise, P.M., Dubal, D.B., Wilson, M.E., Rau, S.W., 2000. Estradiol is a neuroprotective factor in in vivo and in vitro models of brain injury. J. Neurocytol. 29, 401-410.

Wise, P.M., Dubal, D.B., Wilson, M.E., Rau, S.W., Bottner, M., Rosewell, K.L., 2001. Estradiol is a protective factor in the adult and aging brain: understanding of mechanisms derived from in vivo and in vitro studies. Brain Res. Brain Res. Rev. 37, 313-319.

Wolf, O.T., Neumann, O., Hellhammer, D.H., Geiben, A.C., Strasburger, C.J., Dressendorfer, R.A., Pirke, K.M., Kirschbaum, C., 1997. Effects of a two-week physiological dehydroepiandrosterone substitution on cognitive performance and well-being in healthy elderly women and men. J. Clin. Endocrinol. Metab. 82, 2363-2367.

Wolkowitz, O.M., Reus, V.I., Roberts, E., Manfredi, F., Chan, T., Ormiston, S., Johnson, R., Canick, J., Brizendine, L., Weingartner, H., 1995. Antidepressant and cognition-enhancing effects of DHEA in major depression. Ann. N. Y. Acad. Sci. 774, 337-339.

Women's Health Initiative Investigators, 2002. Risks and benefits of estrogen plus progestin in healthy postmenopausal women. J. Am. Med. Assoc. 288, 321-333.

Women's Health Initiative Investigators, 2003a. Effect of estrogen plus progestin and the incidence of dementia and mild cognitive impairment in postmenopausal women. J. Am. Med. Assoc. 289, 2651-2662.

Women's Health Initiative Investigators, 2003b. Effect of estrogen plus progestin on global cognitive function in postmenopausal women. J. Am. Med. Assoc. 289, 2663-2672.

Women's Health Initiative Investigators, 2003c. Effect of estrogen plus progestin on stroke in postmenopausal women. J. Am. Med. Assoc. $289,2673-2684$.
Women's Health Initiative Investigators, 2003d. Effects of estrogen plus progestin on health-related quality of life. N. Engl. J. Med. 348, $1839-1854$.

Wozniak, A., Hutchison, R.E., Morris, C.M., Hutchison, J.B., 1998. Neuroblastoma and Alzheimer's disease brain cells contain aromatase activity. Steroids 63, 263-267.

Xu, H., Gouras, G.K., Greenfield, J.P., Vincent, B., Naslund, J., Mazzarelli, L., Fried, G., Jovanovic, J.N., Seeger, M., Relkin, N.R., Liao, F., Checler, F., Buxbaum, J.D., Chait, B.T., Thinakaran, G., Sisodia, S.S., Wang, R., Greengard, P., Gandy, S., 1998. Estrogen reduces neuronal generation of Alzheimer beta-amyloid peptides. Nat. Med. 4, 447-451.

Yaffe, K., 2001. Estrogens, selective estrogen receptor modulators, and dementia: what is the evidence? Ann. N. Y. Acad. Sci. 949, 215-222.

Yaffe, K., 2003. Hormone therapy and the brain. J. Am. Med. Assoc. 289, 2717-2719.

Yaffe, K., Ettinger, B., Pressman, A., Seeley, D., Whooley, M., Schaefer, C., Cummings, S., 1998a. Neuropsychiatric function and dehydroepiandrosterone sulfate in elderly women: a prospective study. Biol. Psychiatry 43, 694-700.

Yaffe, K., Sawaya, G., Lieberburg, I., Grady, D., 1998b. Estrogen therapy in postmenopausal women: effects on cognitive function and dementia. J. Am. Med. Assoc. 279, 688-695.

Yanase, T., Fukahori, M., Taniguchi, S., Nishi, Y., Sakai, Y., Takayanagi, R., Haji, M., Nawata, H., 1996. Serum dehydroepiandrosterone (DHEA) and DHEA-sulfate (DHEA-S) in Alzheimer's disease and in cerebrovascular dementia. Endocr. J. 43, 119-123.

Yu, W.H., 1989. Survival of motoneurons following axotomy is enhanced by lactation or by progesterone treatment. Brain Res. 491, 379-382.

Yu, L., Romero, D.G., Gomez-Sanchez, C.E., Gomez-Sanchez, E.P., 2002. Steroidogenic enzyme gene expression in the human brain. Mol. Cell. Endocrinol. 190, 9-17.

Zhang, L., Rubinow, D.R., Xaing, G., Li, B.S., Chang, Y.H., Maric, D., Barker, J.L., Ma, W., 2001. Estrogen protects against beta-amyloidinduced neurotoxicity in rat hippocampal neurons by activation of Akt. Neuroreport 12, 1919-1923.

Zwain, I.H., Yen, S.S., 1999a. Dehydroepiandrosterone: biosynthesis and metabolism in the brain. Endocrinology 140, 880-887.

Zwain, I.H., Yen, S.S., 1999b. Neurosteroidogenesis in astrocytes, oligodendrocytes, and neurons of cerebral cortex of rat brain. Endocrinology 140, 3843-3852.

Zumoff, B., Strain, G.W., Miller, L.K., Rosner, W., 1995. Twenty-fourhour mean plasma testosterone concentration declines with age in normal premenopausal women. J. Clin. Endocrinol. Metab. 80, 14291430. 